NBER WORKING PAPER SERIES

\title{
A THEORY OF PARTICIPATION IN OTC AND CENTRALIZED MARKETS
}

\author{
Jérôme Dugast \\ Semih Üslü \\ Pierre-Olivier Weill \\ Working Paper 25887 \\ http://www.nber.org/papers/w25887 \\ NATIONAL BUREAU OF ECONOMIC RESEARCH \\ 1050 Massachusetts Avenue \\ Cambridge, MA 02138 \\ May 2019, Revised September 2021
}

\begin{abstract}
An earlier version of this paper was circulated under the title "Platform Trading with an OTC Market Fringe." We'd like to thank, for fruitful comments and suggestions, the Editor Veronica Guerrieri and the four referees, as well as Ana Babus, David Cimon, Hugues Dastarac, Darrell Duffie, Selman Erol, Valentin Haddad, Peter Hoffmann, Gregor Jarosch, Peter Kondor, Jordi Mondria, Carlos Ramirez, Marzena Rostek, Norman Schürhoff, Zhaogang Song, and Jing Zeng, as well as seminar participants at UCLA, University of Luxembourg, Johns Hopkins University, University of Colorado Boulder, the Federal Reserve Bank of St. Louis, University of Toronto, UC Irvine, Texas A\&M University, Universidad Diego Portales, the Bank of Canada Workshop on Money, Banking, Payments, and Finance, the 2nd LAEF OTC Markets and Securities Workshop at UCSB, the 2018 ASSA Meetings in Philadelphia, the Spring 2018 Midwest Macroeconomics Meetings at UW-Madison, the 2018 Annual Meeting of the Society for Economic Dynamics in Mexico, the CEPR 2018 European Summer Symposium in Financial Markets in Gerzensee, the European Finance Association 2018 Meetings in Warsaw, the Northern Finance Association 2018 Meetings in Charlevoix, the 20th Members Meeting of the Finance Theory Group at CMU, the Spring 2019 Southwest Search and Matching Workshop, the Banque de France-ESSEC 2nd Workshop on OTC Markets: Recent Advances in Research, the 2nd Asset Pricing Conference by LTI, the 15th Annual Central Bank Conference on the Microstructure of Financial Markets. Minghao Pan provided expert research assistance.
\end{abstract}

NBER working papers are circulated for discussion and comment purposes. They have not been peer-reviewed or been subject to the review by the NBER Board of Directors that accompanies official NBER publications.

(C) 2019 by Jérôme Dugast, Semih Üslü, and Pierre-Olivier Weill. All rights reserved. Short sections of text, not to exceed two paragraphs, may be quoted without explicit permission provided that full credit, including $(\odot$ notice, is given to the source. 
A Theory of Participation in OTC and Centralized Markets

Jérôme Dugast, Semih Üslü, and Pierre-Olivier Weill

NBER Working Paper No. 25887

May 2019, Revised September 2021

JEL No. G0,G1

\begin{abstract}
$\underline{\text { ABSTRACT }}$
Should regulators encourage the migration of trade from over-the-counter (OTC) to centralized markets? To address this question, we study a model in which banks make costly decisions to participate in an OTC market, a centralized market, or both markets at the same time. Banks differ in their ability to take large positions, what we call their trading capacity. In equilibrium, intermediate-capacity banks find it optimal to participate in the centralized market. In contrast, low- and high-capacity banks find it optimal to participate in the OTC market, due to an endogenous complementarity. Namely, low capacity banks receive worse terms of trade than in the centralized market but better risk sharing, thanks to the intermediation services offered by high-capacity banks. High-capacity banks receive worse risk sharing than in the centralized market, but profit from the provision of intermediation services to low-capacity banks. While the social optimum has qualitatively similar participation patterns, it prescribes that more customers migrate to the centralized market, and that more dealers enter the OTC market.
\end{abstract}

Jérôme Dugast

Université Paris-Dauphine

Place du Maréchal de Lattre de Tassigny

75016 Paris

France

jerome.dugast@dauphine.psl.eu

Semih Üslü

The Johns Hopkins Carey Business School

100 International Drive

Baltimore, MD 21202

semihuslu@jhu.edu
Pierre-Olivier Weill

Department of Economics

University of California, Los Angeles

Bunche Hall 8283

Los Angeles, CA 90095

and NBER

poweill@econ.ucla.edu

Proofs are available at http://www.nber.org/data-appendix/w25887 


\section{Introduction}

Over-the-counter (OTC) markets have a decentralized structure: trade is bilateral, opaque, and generates substantial price dispersion. A common policy concern is that, in OTC markets, dealers make substantial profits at the expense of customers, who pay high prices for low-quality intermediation services. In response, regulators have made proposals and taken measures to increase investors' participation in centralized markets. ${ }^{1}$ But it is not obvious that such policies are welfare improving, since market participation decisions are endogenous: if customers were not content with the intermediation services provided by dealers, private parties could have successfully offered them to participate in centralized markets. In fact, when there is a centralized market option, volume often concentrates in the OTC market. ${ }^{2}$ Therefore, to make a case for these policies, one must answer the following question: can it be socially optimal for investors to participate in a centralized market, when they find it privately optimal to participate as customers in an OTC market?

To address this question, we study an equilibrium in which investors, called "banks," make costly decisions to participate in an OTC market, a centralized market, or both markets at the same time. Banks are heterogeneous in two dimensions: in their risk-sharing needs, and in their ability to trade large quantities of the asset, what we call their trading capacity. Specifically, we assume that trade size in an OTC bilateral meeting is an increasing function of both counterparties' capacities while, in the centralized market, it is an increasing function of a bank's own trading capacity. Different trading capacities represent differences in funding constraints, access to collateral pool, risk-management technology, or trading expertise.

After deriving general theoretical properties of equilibrium trading patterns and participation incentives, we analyze versions of the model that can be solved in closed form. In our leading specification, banks differ continuously in terms of their capacities, have identical risk sharing need, and face participation costs inducing exclusive participation decisions. As

\footnotetext{
${ }^{1}$ For example, regulators have mandated that some swaps trade multilaterally on platforms called "swap execution facilities." In 2009, G20 Leaders agreed that "all standardized OTC derivative contracts should be traded on exchanges or electronic trading platforms." And, as of June 2017, "12 jurisdictions have in force comprehensive assessment standards or criteria for determining when products should be platform traded, and an appropriate authority regularly assesses transactions against these criteria" (Financial Stability Board, 2017).

${ }^{2}$ For example, Biais and Green (2006) note that "more than 1000 bond issues are still listed on the Exchange" but "the overwhelming majority of trades are conducted over the counter." Riggs, Onur, Reiffen, and Zhu (2018) document that Swap Execution Facilities allow investors to use different execution mechanisms that differ in their degree of centralization. They find that the most centralized mechanism, a limit-order book, attracts very little volume. Holden, Lu, Lugovskyy, and Puzzello (2021) show how in the Chinese Foreign Exchange market, trading activity migrated away from the traditional centralized Limit Order Book to a newly created OTC trading venue.
} 


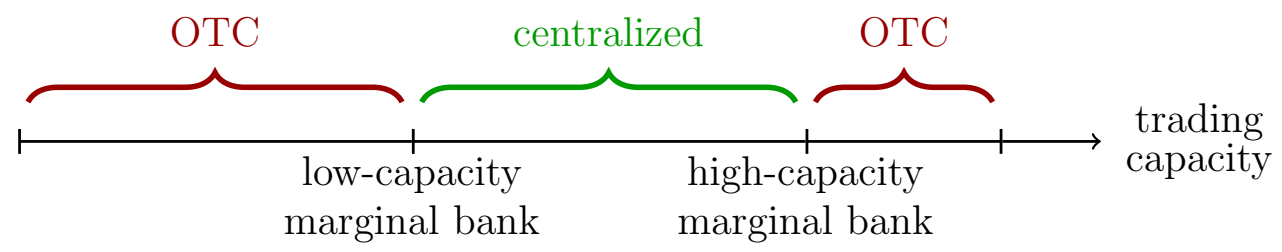

Figure 1: Non-monotonic participation with heterogeneous capacities. Low capacity and high capacity banks choose to participate in the OTC market, while intermediate capacity banks choose to participate in the centralized market. There are two marginal banks, one with a low capacity and one with high capacity.

illustrated by Figure 1, we find that participation decisions are non-monotonic in capacity: banks participate in the OTC market if their capacity is either small or large, and participate in the centralized market if their capacity is intermediate. Low-capacity banks find the OTC market attractive because they can demand intermediation services from high-capacity counterparties. Namely, while low-capacity banks trade at worse terms in the OTC market, their high-capacity counterparties help them establish larger positions than in the centralized market. Correspondingly, high-capacity banks find the OTC market attractive because they can profit from price dispersion by supplying intermediation services to low-capacity banks. Banks with intermediate capacity neither demand nor supply enough intermediation services, and find the centralized market more attractive because it allows them to escape the price discrimination of bilateral bargaining.

The equilibrium participation decisions and trading patterns resemble the observation that OTC markets have two layers of core-periphery structure, one between customers and dealers, and one between dealers (Hollifield, Neklyudov, and Spatt, 2017; Li and Schürhoff, 2019). We argue that low-capacity banks represent customers in practice, while high-capacity banks represent peripheral and core dealers. In equilibrium, peripheral dealers provide intermediation services to customers only, while core dealers provide intermediation services to both customers and peripheral dealers. Finally, the result that banks with intermediate capacity participate in the centralized market echoes the evidence of Holden, Lu, Lugovskyy, and Puzzello (2021) who study parallel OTC and centralized trading in the Chinese Foreign Exchange Market. They show that medium banks participate more in the centralized market than large banks, which corroborates our theoretical prediction that intermediate-capacity banks have the strongest incentives to participate in the centralized market.

Next, we study the welfare impact of reallocating marginal banks from the OTC to the centralized market. When participation is exclusive, this mechanically leads to a decrease in 
OTC market participation, with two effects going in opposite directions. On the one hand, matches are destroyed because the marginal bank, who now participates only in the centralized market, no longer meets other banks in the OTC market. On the other hand, matches are created between the banks who no longer meet the marginal bank. We show that the first effect dominates for high-capacity marginal banks, while the second effect dominates for lowcapacity marginal banks. Indeed, when the low-capacity marginal bank is reallocated to the centralized market, the trades destroyed have smaller size than the trades created, and vice versa for the marginal high-capacity bank. Hence, our welfare analysis suggests that marginal customers should participate more in centralized markets and, perhaps counter-intuitively, marginal peripheral dealers should participate more in OTC markets. A calculation of the social optimum confirms these findings.

In the last part of the paper we study three alternative specifications of the model. These examples illustrate how the analysis of welfare depends on equilibrium participation patterns and on banks' underlying heterogeneity.

In the first specification, participation is non-exclusive and the marginal bank is indifferent between participating in the OTC market only and participating simultaneously in the OTC and the centralized market. In that case, we find that making the marginal OTC banks participate in the centralized on top of the OTC market is welfare reducing. The reason is that, since the bank continues to participate in the OTC market, there is no match creation and destruction. The only effect at play is that, by participating in the centralized market and purchasing extra risk-sharing services, the bank reduces its transaction surplus aggregated across its OTC counterparties. Therefore, we end up with an unambiguous welfare loss in this specification.

Our second specification generates participation patterns similar to the exclusive case (in Figure 1), except that the participation of high-capacity banks is non-exclusive: they trade both in the OTC and the centralized market. We find that the welfare analysis turns out to be very similar to that in the exclusive model, because in this case if a marginal bank changes its optimal decision and moves to the centralized market, it leaves the OTC market. Therefore, in spite of non-exclusivity, reallocating marginal banks to the centralized market induces match creation and destruction in the OTC market.

Taken together, our two examples with non-exclusivity show that our main welfare effects are not driven by exclusivity per se. Instead, they depend on whether reallocating marginal banks to the centralized market induce match creation and destruction in the OTC market. 
Finally, in the third specification, we consider the polar case in which banks have heterogeneous risk sharing needs but homogeneous capacities, and assume exclusive participation. We obtain that banks with strong risk sharing needs find it optimal to participate in the centralized market, while banks with moderate risk sharing needs find it optimal to participate in the OTC market. Amongst the OTC market participant, banks with moderate risk sharing needs supply intermediation services to banks with strong risk sharing needs. In this context, moving the marginal bank to the centralized market is in fact welfare reducing, because the trades destroyed have larger value than the trades created. An implication of these findings is that, in order to evaluate whether encouraging trade in a centralized trading venue is welfare improving, it is crucial to empirically distinguish an economy in which banks differ mostly in terms of trading capacity, from an economy in which banks differ mostly in terms of their risk sharing needs. Our examples suggest the following empirical distinctions. When banks differ mostly in terms of trading capacity, the per-dealer gross trading volume can be much larger than the per-customer gross volume, and the net trading volume of dealers can be large. In contrast, when banks differ mostly in terms of risk sharing needs, dealers and customers have comparable gross trading volume, but dealers have lower net trading volume. Hence, considering tradingvolume patterns in the real-world OTC markets, our analytical examples suggest that banks differ mostly in terms of their trading capacity.

\section{Literature review}

This paper builds on Atkeson, Eisfeldt, and Weill (2015, henceforth AEW), who have developed a tractable framework, using insights from both the search- and network-theoretic literature, to study entry and trading patterns in an OTC market. We generalize AEW in two ways. First, while AEW only considered the margin of participation between autarky and the OTC market, we add a new margin: between the OTC and the centralized markets. This is clearly essential to analyze our main research question. Second, we allow banks to differ in a new dimension, their trading capacities. Heterogeneity in capacities gives rise to rich and realistic participation and trading patterns in OTC and centralized market, and generate new insights about welfare. Finally, the mathematical framework is also more general since we consider general distributions over both risk endowments and trading capacities, instead of discrete distributions over risk endowment only in AEW. While this introduces some technical difficulties, it also has advantages: it provides tools and results that are likely to be useful 
in other applications, it clarifies the economic forces at play, and it leads to closed-form characterizations of equilibrium for some important cases of interest.

A branch of the literature compares the costs and benefits associated with centralized and decentralized trading structures without endogenous participation decision. See, for example, Geromichalos and Herrenbrueck (2016), Liu, Vogel, and Zhang (2018), Li and Song (2019), Vogel (2019), Glode and Opp (2020), and Colliard, Foucault, and Hoffmann (2021). Another branch of the literature has studied the trade-off between exclusive participation in a centralized or a decentralized market. For example, Yavaş (1992), Gehrig (1993), Rust and Hall (2003), Miao (2006), Lee and Wang (2018), and Yoon (2018) considered models in which investors can search for OTC trading counterparties (customers or exogenously specified dealers) or trade with market-makers in a centralized venue, and showed that either venue may dominate from a welfare perspective depending on conditions. ${ }^{3}$ While these papers only considered the way customers trade off between OTC and centralized markets, we also consider the trade-off faced by dealers. That is, in our model, both trading roles and trading venues are endogenous, while the rest of the literature took trading roles as given. This is important because in our main analytical example, we show that the dealer segment of the OTC market is too small while the customer segment is too large from a normative perspective. In addition, we also study non-exclusive participation, i.e., the possibility that investors participate simultaneously in two markets. We show that, in some cases, the normative analysis of non-exclusive participation is conceptually different from that of exclusive participation. ${ }^{4}$

Many recent papers have studied theoretically the emergence of traders with different degree centrality based on alternative assumptions regarding their heterogeneity. A non-exhaustive list of papers includes Babus (2009), Neklyudov (2012), Hugonnier, Lester, and Weill (2014), Afonso and Lagos (2015), Farboodi, Jarosch, and Shimer (2015), Farboodi, Jarosch, and Menzio (2016), Chang and Zhang (2016), Wang (2016), Babus and Kondor (2018), Bethune, Sultanum, and Trachter (2018), and Üslü (2019). Our paper builds on their insights with a different modeling framework to study equilibrium and socially optimal participation in OTC

\footnotetext{
${ }^{3}$ The majority of these papers assume indivisible assets, and so, trade sizes are fixed at one, not leaving any room for heterogeneity in trading capacity. Accordingly, the conditions they derive for welfare improvement are in terms of agents' valuations, the counterpart of risk sharing needs in our model. The other papers with divisible assets such as Yoon (2018) assume agents who are not restricted in their trade size, i.e., agents have "deep pockets." Hence, the conditions for welfare improvement in our leading analytical example with heterogeneous trading capacity are entirely complementary to what has been shown in the literature so far.

${ }^{4}$ Praz (2014) also studied non-exclusive trade within a dynamic equilibrium asset pricing framework, but without endogenous participation. In his model, investors trade two correlated assets in two markets, the first one in a centralized market, and the second one in a decentralized search market.
} 
vs. centralized market. The advantage of our static modeling framework is that it allows for a rigorous, transparent, and simple characterization of the composition externalities induced by participation decisions. In addition, the participation and trading patterns endogenously generate two layers of core-periphery structures in our model: one between customers and dealers, and one between periphery and core dealers. This is reminiscent of OTC markets in practice. While agents differing from one another continuously in terms of their degree centrality in the OTC market is common in the literature, ${ }^{5}$ an endogenous discontinuity in centrality arising due to the presence of a centralized venue is, to the best of our knowledge, a new result.

There is also an IO literature studying endogenous market participation. Mankiw and Whinston (1986) study entry to a product market with imperfect competition and find that an entrant's private incentive to enter may be larger than its social incentive depending on how it affects the incumbent's endogenous supply. McAfee and McMillan (1987), Levin and Smith (1994), and Menezes and Monteiro (2000) study auctions with endogenous participation decision and derive results markedly different from what the auction models with an exogenous set of bidders imply. For example, Levin and Smith (1994) show that limiting the number of potential bidders may be socially desirable, which is contrary to the predictions of models without endogenous participation. Bulow and Klemperer (2009) compare bidders' sequential entry decision to an auction and to a sequential sale mechanism with negotiation. They find that although the sequential sale mechanism always dominates in terms of social welfare, sellers usually prefer the auction. Similar to these studies, we also highlight a discrepancy between the privately and socially optimal outcomes when participation is endogenous. Naturally, our model significantly differs from these studies, because we model bilateral vs. multilateral trading of a perfectly divisible financial asset in a large market, while the mentioned studies focus on trading indivisible products in small markets.

Biais and Mariotti (2005), Axelson (2007), Rostek and Yoon (2018), and Babus and Hachem (2019) study how the market structure affects the optimal security design problem of asset issuers. A few papers have explored the manner in which market fragmentation may emerge as an equilibrium outcome due to information and price-setting frictions, and may dominate a centralized exchange. See Kawakami (2017), Malamud and Rostek (2017), Babus and Parlatore (2017), and Cespa and Vives (2018). We do not seek to explain fragmentation per-se, nor study

\footnotetext{
${ }^{5}$ See Hugonnier, Lester, and Weill (2014), Farboodi, Jarosch, and Shimer (2015), and Üslü (2019), for example.
} 
asset issuance. Instead, we study the privately and socially optimal decisions of investors to participate in two given trading venues. Finally, we also contribute to the assignment literature because we study heterogeneous agents who make market participation decision. ${ }^{6}$ Relative to this literature, our assignment model has two distinct features. First, participation is allowed to be non-exclusive. Second, since the OTC market is frictional, participation incentives are, in part, driven by incentives to demand or supply intermediation services.

The rest of the paper is organized as follows. In Section 2, we lay out our model of participation in an OTC and in a centralized market. In Section 3, we define an equilibrium and study its general properties. In Section 4, we consider analytical examples of the general model, under alternative assumptions about investor heterogeneity and participation costs. Then, we derive our main normative results regarding the social gain/loss from increasing the participation of customers in the centralized market.

\section{Model}

We generalize the model of Atkeson, Eisfeldt, and Weill (2015, henceforth AEW) in two ways. First, banks are heterogeneous in two dimensions: their risk-sharing need and their trading capacity. Second, banks can participate in two markets: an OTC market and a centralized market.

In the next two sections our presentation of the model is deliberately abstract. Our goal is to derive general properties, to highlight that the model is sufficiently flexible to capture a rich two-dimensional heterogeneity in banks' trading needs and trading ability, irrespective of microfoundations and functional forms, and to demonstrate that its results can be applied broadly to many OTC markets. We offer pencil-and-paper examples later, in Section 4.

\subsection{Time, agents, and assets}

There are four dates $t \in\{0,1,2,3\}$, one good consumed at the terminal date, $t=3$, and one divisible risky asset with normally distributed payoff. There is a measure one of traders who have Constant Absolute Risk Aversion (CARA), with the common coefficient $\eta$, over time3 consumption. We assume that traders are organized into a measure one of large coalitions, called "banks." While many non-bank institutions such as hedge funds and insurance companies

\footnotetext{
${ }^{6}$ Some classical examples of the assignment game include Koopmans and Beckmann (1957), Shapley and Shubik (1972), Crawford and Knoer (1981), and Bikhchandani and Ostroy (2002). See Núñez and Rafels (2015) for a recent survey on assignment markets.
} 
trade in asset markets in reality, we employ the label bank, for brevity, to refer to all of them. We assume that banks differ in two dimensions: their risk-sharing needs and their trading capacities.

Differences in risk-sharing needs are generated by heterogeneity in banks' endowment of the risky asset, $\omega \in[0,1]$, where we normalized the upper bound of the endowment to 1 . Since CARA banks have incentives to trade so as to equalize their holdings, ${ }^{7}$ banks have stronger risk-sharing needs if their initial endowment is very large or small relative to the economy-wide average.

We assume as well that banks are heterogeneous in their trading capacities, denoted by $k \in[\underline{k}, \bar{k}]$. Banks with larger $k$ can trade larger quantities in both the OTC market and the centralized markets, in a manner to be precisely explained shortly.

We let $F$ denote the exogenous joint cumulative distribution of endowments and trading capacities, $(\omega, k)$, over the set $[0,1] \times[\underline{k}, \bar{k}]$, equipped with its Borel $\sigma$-algebra. We assume that, given capacity, the distribution of endowments is symmetric: $d F(\omega, k)=d F(1-\omega, k)$ for all $\omega \in[0,1]$.

\subsection{Participation}

At $t=0$, banks make one of the four market participation decisions: they can choose to trade the risky asset in a decentralized OTC market with bilateral bargaining, $\pi=0$, in a centralized market with price taking, $\pi=\mathrm{c}$, or in both markets at the same time, $\pi=$ oc. They can also stay in autarky, $\pi=$ a. We let $\Pi \equiv\{\mathrm{o}, \mathrm{c}, \mathrm{oc}, \mathrm{a}\}$ be the set of all possible participation decisions. After its participation decision, a bank's type is summarized by the triple $x \equiv(\omega, k, \pi)$. We let $\omega(x), k(x)$ and $\pi(x)$ denote the endowment, capacity, and participation decision of type $x$. The cost of participation of type $x$ is denoted by $C(x) \geq 0$. We assume for simplicity that $C(x)$ only depends on $\pi$ and we normalize the cost of autarky to zero.

On aggregate, banks' collective participation decisions induce an endogenous measure $N$ over the set $X$ of all possible bank types, which we call the participation path. The participation path must satisfy a basic conservation condition:

$$
d F(\omega, k)=\sum_{\pi \in \Pi} d N(\omega, k, \pi)
$$

\footnotetext{
${ }^{7}$ Indeed, this is the allocation of assets in any Pareto optimum and, by the First Welfare Theorem, in any competitive equilibrium.
} 
where $d N(\omega, k, \pi)$ denotes the measure of banks with endowment $\omega$, capacity $k$, and participation decision $\pi$. This consistency condition states that the marginal distribution over endowment and trading capacity, $(\omega, k)$ must be consistent with the exogenous distribution $F$. Finally, anticipating a property of equilibrium, we guess throughout that the participation path is symmetric: banks with symmetric endowment and identical capacity make identical participation decisions, $d N(\omega, k, \pi)=d N(1-\omega, k, \pi)$.

\subsection{Trading and payoffs}

The timing of trade after participation decisions have been made is as follows. At $t=1$, banks who chose $\pi \in\{\mathrm{o}, \mathrm{oc}\}$ trade in the OTC market. At $t=2$, banks who chose $\pi \in\{\mathrm{c}, \mathrm{oc}\}$ trade in the centralized market. At $t=3$, every bank consolidates all its traders' positions, and the risky asset pays off. We now describe trades and payoffs in detail.

OTC market trades. Let $X_{\mathrm{o}} \equiv \pi^{-1}(\{\mathrm{o}, \mathrm{oc}\})$ denote the set of banks' types participating in the OTC market, and assume positive OTC market participation, $N\left(X_{\mathrm{o}}\right)>0$. Then, at $t=1$, all banks with type $x \in X_{\mathrm{o}}$ send their traders to the decentralized OTC market, where they are paired uniformly to bargain over a bilateral trade. When a trader from a type- $x$ bank is paired with a trader from a type- $x^{\prime}$ bank, the trader of type $x$ buys a quantity $\gamma\left(x, x^{\prime}\right)$ of assets from the trader of type $x^{\prime}$, in exchange for the payment $P_{\mathrm{o}}\left(x, x^{\prime}\right) \gamma\left(x, x^{\prime}\right)$. A positive $\gamma\left(x, x^{\prime}\right)$ is an outright purchase, and a negative an outright sale. OTC market trades must satisfy an elementary bilateral feasibility constraint and a bilateral capacity constraint:

$$
\begin{aligned}
& \gamma\left(x, x^{\prime}\right)+\gamma\left(x^{\prime}, x\right)=0 \text { for all }\left(x, x^{\prime}\right) \in X^{2} \\
& -\Gamma\left(x^{\prime}, x\right) \leq \gamma\left(x, x^{\prime}\right) \leq \Gamma\left(x, x^{\prime}\right) .
\end{aligned}
$$

for some continuous, positive-valued and symmetric function $\Gamma\left(x, x^{\prime}\right)$. We rule out trade between types who do not participate in the OTC market by assuming that $\Gamma\left(x, x^{\prime}\right)=0$ if $\left(x, x^{\prime}\right) \notin X_{\mathrm{o}}^{2}$. If both types participate in the OTC market, $\left(x, x^{\prime}\right) \in X_{\mathrm{o}}^{2}$, we assume that $\Gamma\left(x, x^{\prime}\right)$ only depends on, and is increasing in capacities $\left(k, k^{\prime}\right)$. The capacity constraint is crucial to our analysis because it prevents banks from fully sharing their risk by trading only in the OTC market. In practice, banks differ in their ability or willingness to let their traders take large positions for reasons such as differences in funding constraints, access to collateral pool, 
risk-management technology, or trading expertise. Taking stock, a collection of OTC market bilateral trades, $\gamma: X^{2} \rightarrow \mathbb{R}$, is feasible if it is measurable and if it satisfies (2) and (3).

Centralized market trades. Let $X_{\mathrm{c}} \equiv \pi^{-1}(\{\mathrm{c}, \mathrm{oc}\})$ denote the set of banks' type participating in the centralized market and assume positive participation, $N\left(X_{\mathrm{c}}\right)>0$. Then, at time $t=2$, banks with types $x \in X_{\mathrm{c}}$ can trade multilaterally at some fixed price $P_{\mathrm{c}}$ in the centralized market. But they are still subject to a capacity constraint: this is natural because the economic forces underlying such constraint, such as risk-management concerns, are presumably at play in the centralized market as well.

With this in mind, we let a collection of centralized market trades be described by some measurable function $\varphi: X \rightarrow \mathbb{R}$. Centralized market trades are feasible if:

$$
\begin{aligned}
& \int \varphi(x) d N(x)=0 \\
& -\Phi(x) \leq \varphi(x) \leq \Phi(x),
\end{aligned}
$$

Condition (4) is the market-clearing condition in the centralized market, while condition (5) is the capacity constraint faced by banks in the centralized market, where $\Phi(x)$ is a positive and continuous function. We rule out trades by banks who do not participate in the centralized market by assuming that $\Phi(x)=0$ if $x \notin X_{\mathrm{c}}$. If $x \in X_{\mathrm{c}}$, we assume that $\Phi(x)$ only depends on, and is increasing in the bank's own capacity $k$.

Consolidation and payoffs. After trading in the OTC and the centralized market, a bank consolidates all its trades. The asset's random payoff, denoted by $v$, realizes. Each trader then receives a consumption equal to the average per-trader payoff of her bank:

$$
-C(x)+\omega(x) v+\int \gamma\left(x, x^{\prime}\right)\left[v-P_{\mathrm{o}}\left(x, x^{\prime}\right)\right] d N\left(x^{\prime} \mid \mathrm{o}\right)+\varphi(x)\left(v-P_{\mathrm{c}}\right),
$$

where $\omega(x)$ is the endowment of a bank of type $x$, and $N\left(x^{\prime} \mid \mathrm{o}\right) \equiv N\left(x^{\prime}\right) / N\left(X_{\mathrm{o}}\right)$. The first term is the participation cost incurred by type $x$. The second term is the payoff of the bank's asset endowment. The third term is the net payoff of OTC-market trades. Finally, the fourth term is the net payoff of centralized-market trades. To calculate the certainty equivalent corresponding to this payoff, we define the bank's post-trade exposure to the risky asset:

$$
g(x) \equiv \omega(x)+\int \gamma\left(x, x^{\prime}\right) d N\left(x^{\prime} \mid \mathrm{o}\right)+\varphi(x)
$$


The first term is the initial endowment, the second term is the exposure gained via OTCmarket trades, and the third term is the exposure gained via centralized-market trades. Then, the certainty-equivalent payoff of the bank writes:

$$
-C(x)+U[g(x)]-\int \gamma\left(x, x^{\prime}\right) P_{\mathrm{o}}\left(x, x^{\prime}\right) d N\left(x^{\prime} \mid \mathrm{o}\right)-\varphi(x) P_{\mathrm{c}}
$$

where $U(g) \equiv \mathbb{E}[v] g-\frac{\eta}{2} \mathbb{V}[v] g^{2}$ is the mean-variance payoff that obtains with CARA utility, absolute risk aversion $\eta$, and normally distributed asset payoff. ${ }^{8}$

\section{Equilibrium}

In this section, we define an equilibrium in two steps. First, we define an equilibrium conditional on participation decisions, summarized by the participation path $N$. Second, we define equilibrium participation decisions, $N$, given rational expectations about subsequent equilibrium trades.

\subsection{Equilibrium trades given participation}

We assume for simplicity that participation is positive in all markets, $N\left(X_{\mathrm{o}}\right)>0$ and $N\left(X_{\mathrm{c}}\right)>0$ (as will be clear, it is straightforward to extend the analysis to the other cases).

Optimal trading in the OTC market. We assume that, in the OTC market, a trader maximizes his marginal impact on his bank's certainty-equivalent payoff, (7):

$$
\gamma\left(x, x^{\prime}\right)\left\{U_{g}[g(x)]-P_{\mathrm{o}}\left(x, x^{\prime}\right)\right\}
$$

where $U_{g}(\cdot)$ is the derivative of $U(\cdot)$, and where an individual trader takes others' decisions as given, as summarized by the post-trade exposure, $g(x)$. In other words, traders view themselves small relative to their bank's coalition, and do not coordinate their trades with other traders in the same bank coalition. ${ }^{9}$

\footnotetext{
${ }^{8}$ Quadratic payoffs are important to ensure that participation incentives and decisions are appropriately symmetric in endowment. That being said, a number of results regarding equilibrium conditional on participation go through even if $v$ is not normally distributed and payoffs are not quadratic, i.e., the concavity of $U$ suffices.

${ }^{9}$ This approach is used extensively in monetary economics literature as well as by AEW. See Lucas (1990), Andolfatto (1996), Shi (1997), and Shimer (2010), among others. It is also the continuum-population analogue of the Nash-in-Nash solution (i.e., the Nash equilibrium in Nash bargains) used in bilateral oligopoly settings with interdependent payoffs. See Horn and Wolinsky (1988), Stole and Zwiebel (1996), Crawford and Yurukoglu (2012), and Collard-Wexler, Gowrisankaran, and Lee (2019), among others. With the assumption of the
} 
Assuming that bilateral trades are the outcome of symmetric Nash bargaining between the two traders, we obtain the following optimality conditions:

$$
\gamma\left(x, x^{\prime}\right)= \begin{cases}\Gamma\left(x, x^{\prime}\right) & \text { if } g(x)<g\left(x^{\prime}\right) \\ \in\left[-\Gamma\left(x^{\prime}, x\right), \Gamma\left(x, x^{\prime}\right)\right] & \text { if } g(x)=g\left(x^{\prime}\right) \\ -\Gamma\left(x^{\prime}, x\right) & \text { if } g(x)>g\left(x^{\prime}\right)\end{cases}
$$

for all $\left(x, x^{\prime}\right) \in X_{\mathrm{o}}^{2}$. That is, if the type- $x$ trader expects a lower post-trade exposure than the type- $x^{\prime}$ trader, then he should purchase some asset. Given that the type- $x$ trader views himself as small relative to his coalition, he finds it optimal to purchase as much as feasible given the bilateral trading capacity constraint (3). The asset price between $x$ and $x^{\prime}$ is set to split the bilateral gains from trade in half:

$$
P_{\mathrm{o}}\left(x, x^{\prime}\right)=\frac{1}{2}\left\{U_{g}[g(x)]+U_{g}\left[g\left(x^{\prime}\right)\right]\right\}
$$

One sees from (8) that OTC market trades tend to bring banks' post-trade exposures closer together, in that banks with small exposures tend to buy from banks with high exposures. However, in general, banks do not equalize their post-trade exposures, for two reasons. First, the trading capacity constraint (3) limits the size of OTC market trades. Second, the bilateral trading protocol implies that traders in the same bank will trade in opposite direction depending on who they meet. For example, type- $x$ traders purchase from type- $x^{\prime}$ traders if $g(x)<g\left(x^{\prime}\right)$, but they sell if $g(x)>g\left(x^{\prime}\right)$. Trades of the same size going in opposite direction net out to zero, and so do not contribute to the equalization of post-trade exposures.

Optimal trading in the centralized market. Taking first-order conditions with respect to $\varphi(x)$, one sees that the optimality condition in the centralized market is:

$$
\varphi(x)= \begin{cases}\Phi(x) & \text { if } g(x)<U_{g}^{-1}\left(P_{\mathrm{c}}\right) \\ \in[-\Phi(x), \Phi(x)] & \text { if } g(x)=U_{g}^{-1}\left(P_{\mathrm{c}}\right) \\ -\Phi(x) & \text { if } g(x)>U_{g}^{-1}\left(P_{\mathrm{c}}\right)\end{cases}
$$

continuum of banks and traders - thus, by allowing each bank to optimize participation and each trader to optimize trading decisions while taking as given decisions of others - we provide abstract results in Propositions 1 and 2 robust to how the various features of the model are microfounded. 
That is, the bank trades as much as allowed by the trading capacity constraint, buying if its post-trade exposure is less than $U_{g}^{-1}\left(P_{\mathrm{c}}\right)$, and selling otherwise.

Definition of equilibrium given participation. An equilibrium given positive participation in all markets, $N\left(X_{\mathrm{o}}\right)>0$ and $N\left(X_{\mathrm{c}}\right)>0$, is a collection $\left(\gamma, \varphi, g, P_{\mathrm{o}}, P_{\mathrm{c}}\right)$ of feasible OTC market bilateral trades, $\gamma$, feasible centralized market trades, $\varphi$, post-trade exposures, $g$, OTC market prices, $P_{\mathrm{o}}$, and a centralized market price, $P_{\mathrm{c}}$, such that (6), (8), (9), and (10) hold.

Notice that our definition of equilibrium requires that the optimality conditions (8) and (10) hold everywhere, even for sets of types that are measure zero according to $N$. This simply means that banks' trading decisions must be optimal both on and off the participation path, which is crucial to evaluate the value of all possible participation decisions and solve for equilibrium. ${ }^{10}$

Existence. To establish existence, we show that an equilibrium allocation, $(\gamma, \varphi, g)$, solves a planning problem. Namely, we consider the social planning problem:

$$
W^{\star}(N)=\sup \int\{U[g(x)]-C(x)\} d N(x),
$$

with respect to square-integrable OTC market trades, $\gamma$, centralized market trades, $\varphi$, feasible $N$-almost everywhere, and post-trade exposures $g$ generated by $(\gamma, \varphi)$ according to (6). We obtain:

Proposition 1. There exists an equilibrium given positive participation in all markets. All equilibria solve the planning problem given participation. The equilibrium is essentially unique in the sense that all equilibria share the same post-trade risk exposures, $g$, prices, $\left(P_{\mathrm{o}}, P_{\mathrm{c}}\right)$, and certainty-equivalent payoff, (7). Finally, equilibrium post-trade exposures are continuous in $x$, symmetric and increasing in endowment, increasing in capacity if $\omega \leq 1 / 2$ and decreasing if $\omega \geq 1 / 2$, larger when a bank participates in the centralized market in addition to the OTC market if $\omega \leq 1 / 2$, and smaller if $\omega \geq 1 / 2$.

The existence proof starts from the observation that all equilibria solve the planner's problem, which follows by direct comparison of the planner's first-order conditions with the equilibrium optimality condition (8)-(10). Next, using standard results on convex optimization

\footnotetext{
${ }^{10}$ Suppose, for example, that some banks with endowments and trading capacities $(\omega, k)$ in some set $A$ only participate in the centralized market. That is, $N(A \times\{\mathrm{c}\})>0$ but $N(A \times\{\mathrm{o}, \mathrm{oc}\})=0$. To verify whether participating only in the centralized market is indeed optimal, banks $(\omega, k) \in A$ evidently need to compare the value of all participation decisions, $\pi \in\{\mathrm{o}, \mathrm{c}, \mathrm{oc}\}$. This means that we need to solve for trades, $(\gamma, \varphi)$, and payoffs for all types $x \in A \times\{\mathrm{o}, \mathrm{c}, \mathrm{oc}\}$, even if some of these types are in measure zero according to $N$.
} 
in infinite dimensional vector spaces (see, for example, Proposition 1.2, Chapter II in Eckland and Témam, 1987), we establish that the planner's problem has at least one solution. Finally, we show that an appropriately selected solution of the planner's problem is the basis of an equilibrium. The key difficulty in completing this step is that the planner's problem has many solutions, since it only cares about those types that have positive measure according to the participation path $N$. Specifically, the planner only needs to determine trading behavior on the participation path, while our definition of equilibrium requires to determine trading behavior both on and off that path. ${ }^{11}$ However, the planner's problem uniquely determines aggregate market conditions: the post-trade exposures of all counterparties that can be met with positive probability in the OTC market, $g(x)$, and the price in the centralized market, $P_{\mathrm{c}}$. This allows us to calculate optimal trading behavior given any off-path participation decision.

The Proposition also establishes intuitive properties of post-trade exposures given any symmetric participation path, $N$. In particular, banks' post-trade exposures are symmetric around the perfect risk-sharing benchmark, $\frac{1}{2}$. Moreover, banks who start with endowments further away from $\frac{1}{2}$ have more difficulties to share risk, in the sense that they end up with a post-trade exposure that is also further away from $\frac{1}{2}$. Finally, banks share risk more effectively if they can trade more, either because they have larger capacities or because they participate in the centralized market in addition to the OTC market.

\subsection{Equilibrium participation}

The certainty equivalent of a type- $x$ bank, before participation cost, can be written:

$$
U[g(x)]-\int \gamma\left(x, x^{\prime}\right) P_{\mathrm{o}}\left(x, x^{\prime}\right) d N\left(x^{\prime} \mid \mathrm{o}\right)-\varphi(x) P_{\mathrm{c}}
$$

The first term is the certainty equivalent utility over post-trade exposure. The second term is the total cost for OTC market trades, and the third term is the total cost of centralized market trades. Using (6), (8) and (9), this formula can be re-written conveniently as follows.

\footnotetext{
${ }^{11}$ Continuing with the example of Footnote 10, consider banks with endowments and trading capacities $(\omega, k)$ in some set $A$ who only participate in the centralized market, $N(A \times\{\mathrm{c}\})>0$ and $N(A \times\{\mathrm{o}, \mathrm{oc}\})=0$. As argued above, the equilibrium requires to determine their payoffs and trades on and off the participation path, that is, for all participation decisions $\pi \in\{\mathrm{c}, \mathrm{o}, \mathrm{oc}\}$. But since these banks only participate in the centralized market, the types $x \in A \times\{\mathrm{o}, \mathrm{oc}\}$ are in zero measure, have zero weight in the planner's objective, and so have indeterminate socially optimal trades.
} 
Lemma 1. Assume that participation is positive in all markets. Then, the certainty equivalent of a bank of type $x \in X,(11)$, can be written

$$
U[\omega(x)]+\operatorname{MPV}(x), \text { with } \operatorname{MPV}(x)=S(x)-\frac{B(x)}{2},
$$

where $\operatorname{MPV}(x)$ is the marginal private value, $S(x)$ the full appropriation surplus, and $B(x)$ the bargaining surplus, defined as:

$$
\begin{aligned}
& S(x) \equiv U[g(x)]-U[\omega(x)]-P_{\mathrm{c}} \varphi(x)-\int U_{g}\left[g\left(x^{\prime}\right)\right] \gamma\left(x, x^{\prime}\right) d N\left(x^{\prime} \mid \mathrm{o}\right) \\
& B(x) \equiv \int\left|U_{g}[g(x)]-U_{g}\left[g\left(x^{\prime}\right)\right]\right| \Gamma\left(x, x^{\prime}\right) d N\left(x^{\prime} \mid \mathrm{o}\right) .
\end{aligned}
$$

Moreover, the marginal private value increases with $k$, decreases with $\omega \in\left[0, \frac{1}{2}\right]$, and symmetrically increases with $\omega \in\left[\frac{1}{2}, 1\right]$.

The marginal private value, or MPV, is the net certainty-equivalent payoff relative to autarky. It can be split into two components.

The first component of the MPV, $S(x)$, is what we call the full appropriation surplus. It is the value of changing exposure, assuming that all assets are bought and sold at the counterparty's marginal value, which is the Walrasian price $P_{\mathrm{c}}$ in the centralized market and the counterparty bank's marginal value $U_{g}\left[g\left(x^{\prime}\right)\right]$ in the OTC market.

But the MPV is smaller than the full appropriation surplus because, for OTC market trades, a bank faces price impact through bilateral bargaining. This can be seen from the fact that Equation (9) depends positively on both counterparties' marginal value. As a result, when a type- $x$ trader expects a lower post-trade exposure than her counterparty, she buys for more than her counterparty marginal value. Vice versa, when she expects a higher post-trade exposure she sells for less than her counterparty's marginal value. The second component of the MPV is the sum of all these OTC bargaining-induced losses for a bank of type- $x$ : it is equal to half of the bargaining surplus, $B(x) / 2$, due to the symmetry in bargaining powers.

Definition of an equilibrium with positive participation. An equilibrium with positive participation in both markets is a positive measure, $N$, over the set of banks' types, $X$, satisfying the following three conditions. First, participation is positive in both markets: $N\left(X_{\mathrm{o}}\right)>0$ and $N\left(X_{\mathrm{c}}\right)>0$. Second, the participation path must satisfy (1), that is, it must be consistent with the primitive exogenous distribution of risk endowment and trading capacities, $F$. Third, the 
participation path must be generated by optimal participation decisions, that is:

$$
\int\left(\operatorname{MPV}(x)-C(x)-\max _{\pi^{\prime} \in \Pi}\left\{\operatorname{MPV}\left(\omega(x), k(x), \pi^{\prime}\right)-C\left(\omega(x), k(x), \pi^{\prime}\right)\right\}\right) d N(x)=0 .
$$

It is conceptually more subtle to define an equilibrium in which participation is zero in one or in both markets, $N\left(X_{\mathrm{o}}\right)=0$ or $N\left(X_{\mathrm{c}}\right)=0$. Indeed, in that case one needs to specify a bank's rational belief regarding its payoff if it chooses to enter a market in which no one else participates. ${ }^{12}$ For the remainder of this paper, we will focus on equilibria in which participation is positive in all markets.

\subsection{Efficient participation: a first-order approach}

In this section, we evaluate the welfare impact of a marginal change in banks' participation. This is useful for at least two reasons. First, it allows to determine whether changes in $N$, such as encouraging more participation in the centralized market, would improve equilibrium welfare. Second, it delivers the first-order necessary conditions of a social optimum.

Let us start with some arbitrary symmetric participation path such that $N\left(X_{\mathrm{o}}\right)>0$ and $N\left(X_{\mathrm{c}}\right)>0$ and consider changes in $N$ of the form:

$$
N+\varepsilon\left(n^{+}-n^{-}\right)
$$

where $\varepsilon$ is a small positive number, while $\left(n^{+}, n^{-}\right)$is a pair of positive and symmetric measures that increase and decrease participation across markets. The pair $\left(n^{+}, n^{-}\right)$of positive and symmetric measures is admissible if it satisfies two natural conditions. First, the participation path $N+\varepsilon\left(n^{+}-n^{-}\right)$must satisfy (1), so as to conserve the distribution of endowments and trading capacities. ${ }^{13}$ Second, the new participation path $N+\varepsilon\left(n^{+}-n^{-}\right)$must remain positive for all $\varepsilon$ small enough. Formally, we require that $n^{-}$is absolutely continuous with respect to $N$, with a bounded Radon-Nikodym derivative.

From Proposition 1, we know that equilibrium social welfare given the participation path $N+\varepsilon\left(n^{+}-n^{-}\right)$solves an optimization problem: it is equal to $W^{\star}\left[N+\varepsilon\left(n^{+}-n^{-}\right)\right]$, the

\footnotetext{
${ }^{12}$ One possible choice of beliefs is to assume that, if no one else participates in a market, then the payoff of participation is zero. But this creates coordination failures: no participation is always an optimal choice if the market is expected to be empty. Another choice is to assume that some infinitesimal exogenous measure of banks participate in all markets at no cost. Finally, one could also attempt to specify beliefs in the spirit of subgame perfection, as in a competitive search equilibrium. That is, if a bank chooses to enter in an empty market, it expects to attract the banks who have most incentives to enter.

${ }^{13}$ Equivalently, $\left(n^{+}, n^{-}\right)$must satisfy the conservation equation: $\sum_{\pi \in \Pi} d n^{+}(\omega, k, \pi)=\sum_{\pi \in \Pi} d n^{-}(\omega, k, \pi)$.
} 
maximized value of the social planner's objective given the participation path $N+\varepsilon\left(n^{+}-n^{-}\right)$. This observation allows us to use Envelope Theorems to calculate the derivative of social welfare with respect to $\varepsilon$. Precisely, adapting arguments from Milgrom and Segal (2002), we obtain:

Proposition 2. Assume participation is positive in all markets and $N$ is symmetric, and consider any admissible $\left(n^{+}, n^{-}\right)$. Then, the function $\varepsilon \mapsto W^{\star}\left[N+\varepsilon\left(n^{+}-n^{-}\right)\right]$is right-hand differentiable at $\varepsilon=0$, with derivative:

$$
\begin{aligned}
& \frac{d}{d \varepsilon}\left[W^{\star}\left(N+\varepsilon\left(n^{+}-n^{-}\right)\right]\left(0^{+}\right)=\int\{\operatorname{MSV}(x)-C(x)\}\left[d n^{+}(x)-d n^{-}(x)\right]\right. \\
& \text { with } \operatorname{MSV}(x) \equiv \operatorname{MPV}(x)+\mathbb{I}_{\left\{x \in X_{\circ}\right\}} \frac{1}{2}[B(x)-\bar{B}],
\end{aligned}
$$

where $\operatorname{MPV}(x)$ is the marginal private value, defined in Lemma 1, $B(x)$ is the equilibrium bargaining surplus given participation path $N$, defined in (12), and $\bar{B}=\int B\left(x^{\prime}\right) d N\left(x^{\prime} \mid \mathrm{o}\right)$ is the average equilibrium bargaining surplus across banks who participate in the OTC market.

The Proposition shows that, when a bank participates exclusively in the centralized market, then the marginal social and private values are equalized, $\operatorname{MSV}(x)=\operatorname{MPV}(x)$. It is intuitive that price taking aligns private and social incentives, even in the presence of capacity constraints.

However, the Proposition also shows that when a bank participates in the OTC market, $x \in X_{\mathrm{o}}$, there is a wedge between the marginal social value and the marginal private value, $\operatorname{MSV}(x)-\operatorname{MPV}(x)=\frac{1}{2}[B(x)-\bar{B}]$. As in the classical welfare analysis of matching models (see, e.g. Hosios, 1990), the wedge arises because OTC market prices do not incorporate the social value and cost of match creation and destruction induced by OTC market participation.

Participation induces match creation simply because a new participant trades with incumbents. The social value of match creation is equal to the bargaining surplus, $B(x)$. However, when they bargain, banks only appropriate half of the social value of match creation. The other half of the bargaining surplus, $B(x) / 2$, drives a wedge between the MSV and the MPV.

But match creation has an opportunity cost: when a new participant matches with incumbents, incumbents match less together. This is what we call match destruction. To calculate the quantity and social value of these destroyed matches, notice first that the creation of a match between a new participant and an incumbent requires just one incumbent trader. The destruction of a match between incumbents frees up exactly two incumbent traders. Hence, the quantity of match destroyed per match created is equal to one half. Moreover, the matching protocol implies that matches are destroyed at random in the populations of incumbents. Hence, 
the average social value of a match destroyed is equal to the average bargaining surplus. Taken together, these observations imply that the social cost of match destruction is equal to half of the average bargaining surplus, $\bar{B} / 2$.

We now study the welfare implications of reallocating a marginal bank from the OTC to the centralized market. We show that the analysis depends crucially on whether the reallocation induces match creation and destruction in the OTC market.

Marginal bank reallocation with match creation and destruction. Consider an equilibrium in which a marginal bank is indifferent between participation in the OTC market, with a type $x$ such that $\pi(x) \in\{\mathrm{o}, \mathrm{oc}\}$, and exclusive participation in the centralized market, with a type $x^{\prime}$ such that $\pi\left(x^{\prime}\right)=\mathrm{c}$ (we provide an analytical example of such equilibria in Section 4). If this bank changes its participation decision from $\pi \in\{\mathrm{o}, \mathrm{oc}\}$ to $\pi=\mathrm{c}$, its type becomes $x^{\prime}$ instead of $x$ and Proposition 2 implies that welfare changes by

$$
\Delta W=\operatorname{MSV}\left(x^{\prime}\right)-C\left(x^{\prime}\right)-(\operatorname{MSV}(x)-C(x))
$$

Using the indifference condition $\operatorname{MPV}\left(x^{\prime}\right)-C\left(x^{\prime}\right)=\operatorname{MPV}(x)-C(x)$ between the OTC market and the centralized market,

$$
\Delta W=\operatorname{MSV}\left(x^{\prime}\right)-\operatorname{MPV}\left(x^{\prime}\right)-[\operatorname{MSV}(x)-\operatorname{MPV}(x)]=\frac{1}{2}[-B(x)+\bar{B}],
$$

where the second equality follows because, as noted before, exclusive participation in the centralized market aligns private with social values. To understand this formula, recall that when the marginal bank is reallocated to the centralized market, it no longer matches with inframarginal OTC banks, with social cost equal to the bargaining surplus, $B(x)$. But infra-marginal OTC banks substitute their match with the marginal bank by matches amongst themselves, with social value equal to the average bargaining surplus, $\bar{B}$. The formula shows that, if $B(x)<\bar{B}$, then the reallocation of marginal banks from the OTC market to the centralized market is welfare improving. Inspecting the bargaining-surplus formula of Lemma 1, it is clear that $B(x)$ will be smaller than $\bar{B}$, and so, $\Delta W>0$, if:

1. the trades of the marginal bank have a sufficiently small size, measured by $\Gamma\left(x, x^{\prime}\right)$, relative to the average,

2. the trades of the marginal bank create a small enough surplus per quantity traded, measured by $\left|U_{g}[g(x)]-U_{g}\left[g\left(x^{\prime}\right)\right]\right|$, relative to the average. 
These two conditions depend on endogenous outcomes, specifically on the participation path $N$ and on the post-trade exposure, $g(x)$. In the next section, we develop analytical examples that illustrate how these two conditions depend on exogenous parameters.

Marginal bank reallocation without match creation and destruction. Now let us consider an equilibrium in which a marginal bank is indifferent between trading exclusively in the OTC market, with a type $x$ such that $\pi(x)=0$, and trading in both the OTC and the centralized market, with a type $x^{\prime}$ such that $\pi\left(x^{\prime}\right)=$ oc. Proceeding as above we obtain a different formula for the social value of reallocation:

$$
\Delta W=\frac{1}{2}\left[-B(x)+B\left(x^{\prime}\right)\right] .
$$

Relative to (13), this new formula replaces the average surplus, $\bar{B}$, by the bargaining surplus of the bank when it trades in the OTC and the centralized market at the same time. This is because, when participation is non exclusive, there is no match creation and destruction: the bank continues to trade in the OTC market. But its bargaining surplus changes, since it has access to the centralized market.

The formula of Lemma 1 now suggests a different condition for a welfare improvement: the reallocation of a marginal bank to from $\pi=\mathrm{o}$ to $\pi=\mathrm{oc}$ must increase its surplus per quantity traded in the OTC market. However, Proposition 1 implies that this condition can never be satisfied because a bank who trades in the centralized market on top of the OTC market moves closer to the full risk sharing benchmark, and so, reduces its surplus per trade with other OTC banks, $B\left(x^{\prime}\right)<B(x)$.

\section{Analytical examples}

In this section we study tractable parametric examples. This allows us to fill gaps left in the previous section: in particular, we establish equilibrium existence at the participation stage, we characterize patterns of participation and trade, and we compare systematically the equilibrium and the social optimum.

\subsection{Heterogeneous capacities and exclusive participation}

In our main example, we assume that capacities are heterogeneous across banks: they are distributed according to a continuous and strictly positive density $f(k)$ over the compact interval 
$[\underline{k}, \bar{k}]$. To focus on the implications of heterogeneous capacities, we assume that risk-sharing needs are the same for all banks: namely, the endowment distribution has just two points, $\omega=0$, or $\omega=1$, with equal probability, and is independent from capacities. Therefore, $\omega=0$ banks are the natural buyers while $\omega=1$ banks natural sellers. While they trade in opposite directions, $\omega=0$ and $\omega=1$ banks have identical participation incentives as long as they have identical capacities. ${ }^{14}$

It is not obvious how to best specify the bilateral trading capacity constraint, $\Gamma\left(k, k^{\prime}\right)$, since we do not provide precise micro-foundations. We argue that it should satisfy a natural property: the quantity traded in a bilateral trade should depend positively on the capacities of both counterparties. For example, in practice, there is much more customer-to-dealer volume than customer-to-customer volume. Viewed through the lens of our model, this means that lowcapacity customers are able to substantially increase the size of their transactions when they trade with high-capacity dealers. ${ }^{15}$ To capture such effect in a tractable way, we assume that, in the OTC market, bilateral trades are subject to the separable capacity constraint $\Gamma\left(k, k^{\prime}\right)=$ $\left(k+k^{\prime}\right) / 2 .{ }^{16}$ Likewise, in the centralized market, the capacity constraint is $\Phi(k)=(k+K) / 2$, where $K$ represents the capacity of the centralized exchange. We assume that $K \in(0,1)$ so that the centralized market is imperfect. ${ }^{17}$

Finally, we assume for now that banks pay identical cost $C \geq 0$ to participate either in the OTC market $(\pi=0)$ or in the centralized market $(\pi=\mathrm{c})$. As we focus on equilibria with symmetric participation, the centralized market price is $U_{g}\left(\frac{1}{2}\right)$.

Equilibrium conditional on participation. We first show that:

\footnotetext{
${ }^{14}$ This property means that the same equilibrium would obtain if banks made their participation decision ex ante, before learning about their endowment. In this sense, participation does not depend on transitory changes in endowments but only on capacity.

${ }^{15}$ For a theoretical motivation, consider the recent work of Üslü (2019), who studies a dynamic model where trade quantities are determined bilaterally on the margin without any exogenous restrictions. He shows that, as a result of dealers' endogenous willingness to trade in large quantities, trading with a dealer enables a customer to trade in large quantities that would not be possible in a trade with another customer.

${ }^{16}$ Since we are allowing for a general density function, $f(k)$, the restriction imposed by this functional form is not linearity but separability. Formally, consider any separable capacity constraint of the form $h(\ell)+h\left(\ell^{\prime}\right)$, for some strictly increasing and differentiable function $h$ and some capacity $\ell$ that is distributed according to some continuous and strictly positive density. Then, after the change of variable $k=2 h(\ell)$, this separable constraint becomes equivalent to the linear constraint considered here.

${ }^{17}$ One may be concerned that our result rely strongly on the separability of the capacity constraint. To alleviate this concern, in Online Appendix D, we also consider the "max" capacity constraint, that is $\Gamma\left(k, k^{\prime}\right)=\max \left\{k, k^{\prime}\right\}$ and $\Phi(k)=\max \{k, K\}$, and we show our main results still hold.
} 
Lemma 2. Given any $N$ with exclusive participation, an $\omega=0$ bank with capacity $k$ attains the following post-trade exposure and marginal private values:

$$
\begin{aligned}
& g(0, k, \mathrm{c})=\frac{1}{2} \min \{k+K, 1\} \quad \text { and } \quad \operatorname{MPV}(0, k, \mathrm{c})=\frac{\left|U_{g g}\right|}{2} g(0, k, \mathrm{c})[1-g(0, k, \mathrm{c})] \\
& g(0, k, \mathrm{o})=\bar{g}_{\mathrm{o}} \quad \text { and } \operatorname{MPV}(0, k, \mathrm{o})=\frac{\left|U_{g g}\right|}{8}\left(2 \bar{g}_{\mathrm{o}}+k\left(1-2 \bar{g}_{\mathrm{o}}\right)\right) \text {. }
\end{aligned}
$$

where $\bar{g}_{\mathrm{o}} \equiv \frac{1}{2} \min \left\{\mathbb{E}\left[k^{\prime} \mid \mathrm{o}\right], 1\right\}$ and $\mathbb{E}\left[k^{\prime} \mid \mathrm{o}\right] \equiv \int k\left(x^{\prime}\right) d N\left(x^{\prime} \mid X_{\mathrm{o}}\right)$ is the average capacity amongst OTC market participants. Finally, the post-trade exposures of $\omega=1$ banks are symmetric to that of $\omega=0$ banks, and their marginal private values are the same.

Given that the centralized market price is $U_{g}\left(\frac{1}{2}\right)$, centralized market trades bring post-trade exposures as close as possible to $\frac{1}{2}$, subject to capacity constraints.

A perhaps surprising result is that, regardless of $N$, the OTC market equilibrium has an atom property: banks with identical endowment equalize their post-trade exposures, even though they have different capacities. For example, a bank with $k \geq 1$ in the OTC market has sufficient capacity to attain the full-risk sharing post-trade exposure, $\frac{1}{2}$. Yet it chooses a lower one, $\bar{g}_{\mathrm{o}}<\frac{1}{2}$.

To gain intuition for this atom property, consider banks' equilibrium trades when $\bar{g}_{\mathrm{o}}<\frac{1}{2}$. Since $\bar{g}_{\mathrm{o}}<1-\bar{g}_{\mathrm{o}}$, an $\omega=0$ bank always buys quantity $\left(k+k^{\prime}\right) / 2$ from an $\omega=1$ bank. This implies that $\omega=0$ banks with high capacity purchase large quantities from $\omega=1$ banks, while $\omega=0$ banks with low capacity purchase small quantities. This gives $\omega=0$ banks incentive to trade together in an effort to equalize their exposures. The Lemma shows that this leads to complete equalization: banks with identical $\omega$ have identical post-trade exposures, regardless of their capacity $k .^{18}$.

One can in fact verify that, when two $\omega=0$ banks meet, an equilibrium trade is that the $k$ bank purchases the quantity

$$
\frac{k^{\prime}-k}{2}
$$

from the $k^{\prime}$ bank. This means that high-capacity $\omega=0$ banks always sell to low-capacity $\omega=0$ banks. In that sense, high capacity banks play the role of intermediaries: they buy from $\omega=1$

\footnotetext{
${ }^{18}$ This result is not special to the separable trading capacity constraint. One can show for example that it holds whenever $\Gamma\left(k, k^{\prime}\right)$ is submodular in capacities. See Appendix $\mathrm{C}$
} 
banks and re-sell to $\omega=0$ banks. Low capacity banks, on the other hand, play the role of customers: they buy both from $\omega=1$ banks and from other $\omega=0$ banks. ${ }^{19}$

Optimal participation. Lemma 2 reveals as well that the MPVs of participating in the two markets have different properties, as shown in Figure 2. While the MPV of centralized market participation is a concave and bounded function of $k$, the MPV of OTC market participation is linear and increasing in $k$, with a strictly positive slope if $\bar{g}_{\mathrm{o}}<\frac{1}{2}$. Taken together and keeping in mind that participation costs are the same in both markets, one sees from Figure 2 that the equation

$$
\operatorname{MPV}(0, k, \mathrm{o})=\operatorname{MPV}(0, k, \mathrm{c})
$$

has at most two intersections. ${ }^{20}$ One easily verifies that one of these is $k^{\star \star}=1$. Let us denote the other intersection, if it exists, by $k^{\star}<1$. We obtain:

Lemma 3. If banks participate in both markets and if $\bar{g}_{\mathrm{o}}<\frac{1}{2}$, then optimal participation decisions are:

$$
\pi(0, k)=\pi(1, k)= \begin{cases}\text { o } & \text { if } k \in\left[\underline{k}, k^{\star}\right] \\ \mathrm{c} & \text { if } k \in\left(k^{\star}, 1\right) \\ 0 & \text { if } k \in[1, \bar{k}],\end{cases}
$$

for some $k^{\star} \in[\underline{k}, 1-K]$. Moreover $\bar{g}_{\mathrm{o}}>(k+K) / 2$ for all $k \in\left[\underline{k}, k^{\star}\right]$.

Consider first the trade-off faced by $\omega=0$ banks with low capacity, $k<k^{\star}$. The Lemma shows that, for these banks $\bar{g}_{\mathrm{o}}>(k+K) / 2$, which means that the OTC market allows them to trade larger quantities than the centralized market. Indeed, in the centralized market, these banks would have to rely solely on their own trading capacity, while in the OTC market they can benefit from the intermediation services provided by $\omega=0$ banks with high capacities

\footnotetext{
${ }^{19}$ Because all $\omega=0$ banks have the same post-trade exposures, $\bar{g}_{\mathrm{o}}$, the optimal bilateral trades are in fact indeterminate. However, they cannot be arbitrary. In particular, the net trades are determinate: one can easily confirm that high-capacity $\omega=0$ banks sell to other $\omega=0$ banks, while low-capacity banks buy from other $\omega=0$ banks.

${ }^{20}$ If participation costs are not equal, then the equations remain almost the same: one simply need to subtract $C(\mathrm{o})$ and $C(\mathrm{c})$ on the left- and right-hand sides. In Figure 2 this merely shifts the two MPV curves down, so it does not impact the qualitative prediction about participation patterns.
} 


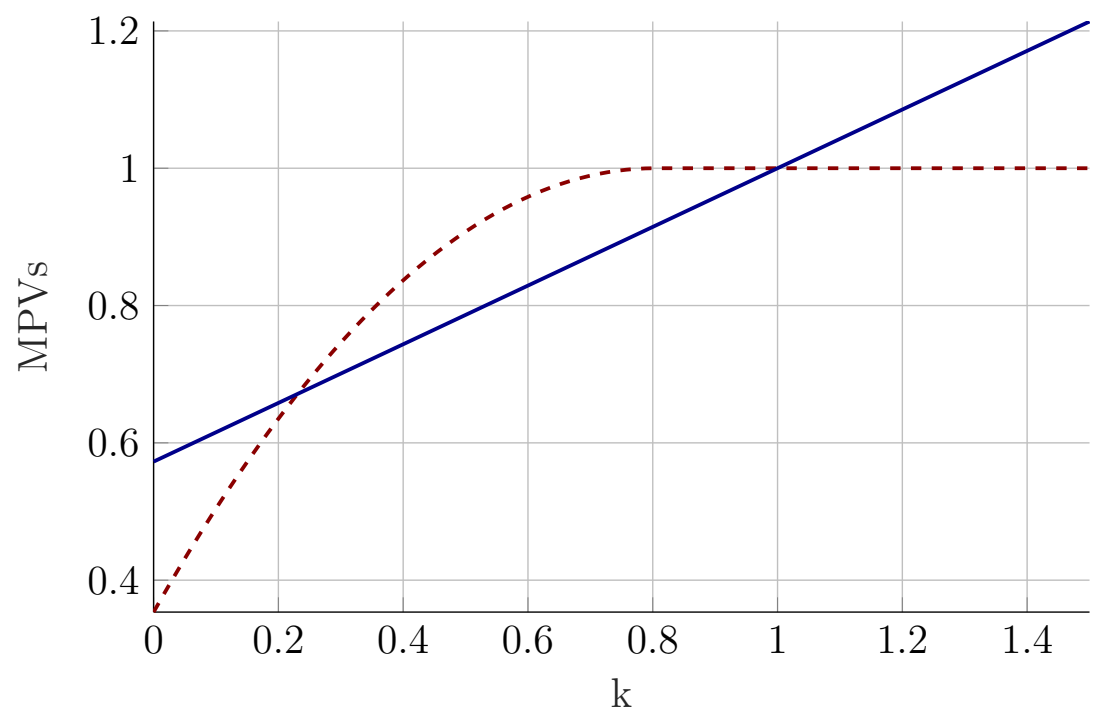

Figure 2: The MPV of centralized (red dashed curve) and OTC market participation (blue plain line, as functions of capacity, $k$.

$k>1$. But these services are costly because bargaining creates price impact: $k<k^{\star}$ banks buy at the high price $U_{g}\left(\bar{g}_{\mathrm{o}}\right)$ instead of the lower centralized market price $U_{g}\left(\frac{1}{2}\right){ }^{21}$

Next, consider the trade-off faced by $\omega=0$ banks with high capacities, $k>1$. These banks could obtain full risk sharing and attain a post-trade exposure of $\frac{1}{2}$ in the centralized market, at a price $U_{g}\left(\frac{1}{2}\right)$. Yet, they prefer to enter the OTC market because they can profit from price dispersion by providing intermediation services. Namely, they are net sellers to other $\omega=0$ banks and are able to bargain a high price $U_{g}\left(\bar{g}_{\mathrm{o}}\right)>U_{g}\left(\frac{1}{2}\right)$.

In summary, banks participate in the OTC market if their capacity is either small or large, and participate in the centralized market if their capacity is intermediate. Low-capacity banks find the OTC market attractive because they can trade with high-capacity banks, from whom they demand intermediation services. Vice versa, high-capacity banks find the OTC market attractive because they can profit from price dispersion by supplying intermediation services to low-capacity banks. Banks with intermediate capacity neither demand nor supply sufficient intermediation services, and find the centralized market more attractive because the trade is multilateral at a fixed price instead of bilateral at dispersed prices.

The optimal participation patterns above are reminiscent of the observation that OTC markets have two layers of "core-periphery" structure, one between customers and dealers, and one between dealers (Hollifield, Neklyudov, and Spatt, 2017; Li and Schürhoff, 2019;

\footnotetext{
${ }^{21}$ As it turns out, there is no price impact in bilateral meetings between $\omega=0$ and $\omega=1$ banks, since the price is $\frac{1}{2}\left[U_{g}\left(\bar{g}_{\mathrm{o}}\right)+U_{g}\left(1-\bar{g}_{\mathrm{o}}\right)\right]=U_{g}\left(\frac{1}{2}\right)$.
} 
Hendershott, Li, Livdan, and Schürhoff, 2020). To be more precise, let us map banks with $k \leq k^{\star}$ to customers in practice, and banks with $k \geq 1$ to peripheral and core dealers in order of increasing capacity. That is, the marginal dealers $(k \simeq 1)$ are the most peripheral ones. Then, according to the equilibrium bilateral trades of Equation (14), peripheral dealers provide intermediation services to customers only, and core dealers provide intermediation services to both customers and peripheral dealers. Therefore, as emphasized by many studies, a coreperiphery structure arises both in the customer-to-dealer market, and in the inter-dealer market.

Another implication of our analysis is that core dealers have the strongest incentives to participate in the OTC market, while peripheral dealers are almost indifferent between operating as a small dealer in the OTC market and using centralized trading just to satisfy their own trading need. Holden, Lu, Lugovskyy, and Puzzello (2021) study how, in 2006, the Chinese Foreign Exchange Market introduced an OTC trading venue in addition to their existing centralized limit order book. They document in particular that large banks migrated more to the OTC market than medium banks. This corroborates our theoretical prediction that high-capacity banks have the strongest incentives to participate in the OTC market.

Existence and uniqueness. Establishing the existence of an equilibrium with $\bar{g}_{\mathrm{o}}<1 / 2$ boils down to solving the equation:

$$
\operatorname{MPV}\left(0, k^{\star}, \mathrm{o} \mid \bar{g}_{\mathrm{o}}\left(k^{\star}\right)\right)=\operatorname{MPV}\left(0, k^{\star}, \mathrm{c}\right),
$$

where we made the marginal private value of participating in the OTC market an explicit function of $\bar{g}_{\mathrm{o}}\left(k^{\star}\right)=\frac{1}{2} \min \left\{\mathbb{E}\left[k^{\prime} \mid k^{\prime} \leq k^{\star}\right.\right.$ or $\left.\left.k^{\prime} \geq 1\right], 1\right\}$. Working out properties of this equation, we establish:

Proposition 3. Suppose that the market participation cost $C$ is small enough. If $\bar{k} \leq 1$, only the centralized market can be active. If $\bar{k}>1$, then there exists a unique equilibrium with two active markets. Moreover, $\bar{g}_{\mathrm{o}}<\frac{1}{2}$ if and only if $\mathbb{E}\left[k^{\prime} \mid k^{\prime}<1-K\right.$ or $\left.k^{\prime} \geq 1\right]<1$.

If $\bar{k} \leq 1$ then large-capacity banks cannot supply sufficient intermediation services to attract low-capacity banks in the OTC market, and only the centralized market can be active. If $\mathbb{E}\left[k^{\prime} \mid k^{\prime}<1-K\right.$ or $\left.k^{\prime} \geq 1\right] \geq 1$, then there is sufficient capacity in the OTC market to attain full risk sharing and $\bar{g}_{\mathrm{o}}=\frac{1}{2}$. Otherwise, there is imperfect risk sharing. 
Comparative statics. How does the size of the OTC market depend on the riskiness of the asset? In our setting, an increase in risk translates into an increase in $\left|U_{g g}\right|$, the curvature of the certainty equivalent.

Lemma 4. Suppose that $\mathbb{E}\left[k^{\prime} \mid k^{\prime}<1-K\right.$ or $\left.k^{\prime} \geq 1\right]<1$ and $C(\mathrm{o}) \simeq C(\mathrm{c})$. Then:

- Participation in the OTC market decreases in $\left|U_{g g}\right|$ if $C(\mathrm{o})<C(\mathrm{c})$;

- Participation in the OTC market increases in $\left|U_{g g}\right|$ if $C(\mathrm{o})>C(\mathrm{c})$.

The intuition is that, when the asset is riskier, the marginal bank becomes more willing to receive risk-sharing services in the market with highest participation cost. This is because the participation cost differential per unit of risk becomes smaller as the asset becomes riskier. Hence, if $C(\mathrm{o})<C(\mathrm{c})$, an increase in risk causes banks to participate more in the centralized market, and vice versa.

If one believes that safer securities tend to trade in OTC markets, while riskier securities tend to trade in centralized markets, then Lemma 4 suggests that $C(\mathrm{o})<C(\mathrm{c})$. Consistent with this view, de Rourea, Moench, Pelizzon, and Schneider (2020) study the market for Bunds (German sovereign bonds) where exchange and OTC trading coexist, and find that trading on the exchange is more likely on days with high intraday volatility or for Bunds with long maturities.

Welfare. As argued in Section 3.3, moving the marginal bank to the centralized market is optimal if and only if its bargaining surplus $B(k)$ is smaller than the average $\bar{B}$. In turn, one easily sees that

$$
B(0, k, \mathrm{o})-\bar{B}=\frac{1}{2} \frac{U_{g}\left(\bar{g}_{\mathrm{o}}\right)-U_{g}\left(1-\bar{g}_{\mathrm{o}}\right)}{2} \frac{k-\mathbb{E}\left[k^{\prime} \mid \mathrm{o}\right]}{2}
$$

Suppose there is partial risk sharing, $\bar{g}_{\mathrm{o}}<\frac{1}{2}$, and consider moving the marginal low-capacity bank, $k^{\star}$, from the OTC to the centralized market. From Lemma 2 and Lemma 3 we obtain that $\bar{g}_{\mathrm{o}}=\mathbb{E}\left[k^{\prime} \mid \mathrm{o}\right] / 2>\left(k^{\star}+K\right) / 2$, which implies that $\mathbb{E}\left[k^{\prime} \mid \mathrm{o}\right]>k^{\star}$. Therefore, moving the $k^{\star}$ bank to the centralized market is welfare improving. In contrast, moving the marginal highcapacity bank, $k^{\star \star}=1$, is welfare reducing. This follows immediately because $\bar{g}_{\mathrm{o}}<\frac{1}{2}$ implies that $\mathbb{E}\left[k^{\prime} \mid \mathrm{o}\right]<1=k^{\star \star}$.

To summarize, marginal dealers impose a positive externality on others thanks to their higher-than-average trading capacity, while marginal customers impose a negative externality on 
others due to their lower-than-average trading capacity. Indeed, marginal dealers create larger surplus than they destroy: they engage in large trades in the OTC market, while destroying, on average, smaller trades. The opposite is true for marginal customers. Accordingly, the social planner wants more participation in the OTC market from marginal dealers and less participation from marginal customers, relative to the equilibrium.

One can also provide an analysis of socially optimal participation patterns, when the social planner's problem is to choose a symmetric participation path $N$ in order to maximize utilitarian welfare. Using the marginal social value formula of Proposition 2 to analyze the first-order conditions of this problem, we obtain:

Proposition 4. Suppose the market participation cost $C$ is small enough and that $\bar{k}>1$. Then, there exists a solution of the planner's problem in which banks participate in both markets, and banks with $k \geq 1$ participate in the OTC market. The planner's solution features partial risk sharing if and only if $\mathbb{E}\left[k^{\prime} \mid k^{\prime}<1-K\right.$ or $\left.k^{\prime} \geq 1\right]<1$. Moreover, in this partial risk-sharing case, the social optimum is characterized by two thresholds $\underline{k} \leq k_{\mathrm{opt}}^{\star} \leq k_{\mathrm{opt}}^{\star \star}<1$, such that

$$
\pi_{\mathrm{opt}}(0, k)=\pi_{\mathrm{opt}}(1, k)= \begin{cases}\mathrm{o} & \text { if } k \in\left[\underline{k}, k_{\mathrm{opt}}^{\star}\right] \\ \mathrm{c} & \text { if } k \in\left(k_{\mathrm{opt}}^{\star}, k_{\mathrm{opt}}^{\star \star}\right) \\ \mathrm{o} & \text { if } k \in\left[k_{\mathrm{opt}}^{\star \star}, \bar{k}\right] .\end{cases}
$$

The Proposition first shows that the social optimum and the equilibrium have qualitatively similar participation patterns: participation is non monotonic and characterized by two thresholds. But, whenever there is partial risk sharing, the thresholds are not the same, implying that the equilibrium is not a social optimum. In particular, since $k_{\mathrm{opt}}^{\star \star}<1$, the planner finds it optimal to bring more dealer (high capacity) banks in the OTC market.

The planner's first-order conditions provide closed-form solutions for entry thresholds as a function of $\bar{g}_{\mathrm{o}}$, which facilitates the numerical computation of a social optimum. Figure 3 plots the participation thresholds in the social optimum as a function of the centralized market capacity, $K$. One sees that, in a social optimum, there is less participation of low-capacity banks and, as we already know from the Proposition, more participation of large-capacity banks. The effect on OTC market size turns out to be ambiguous: in this numerical example, the socially optimal OTC market is larger than the equilibrium for low $K$, and smaller for large $K$. Finally, Figure 4 shows that, conditional on participating in the OTC market, risk sharing improves in 


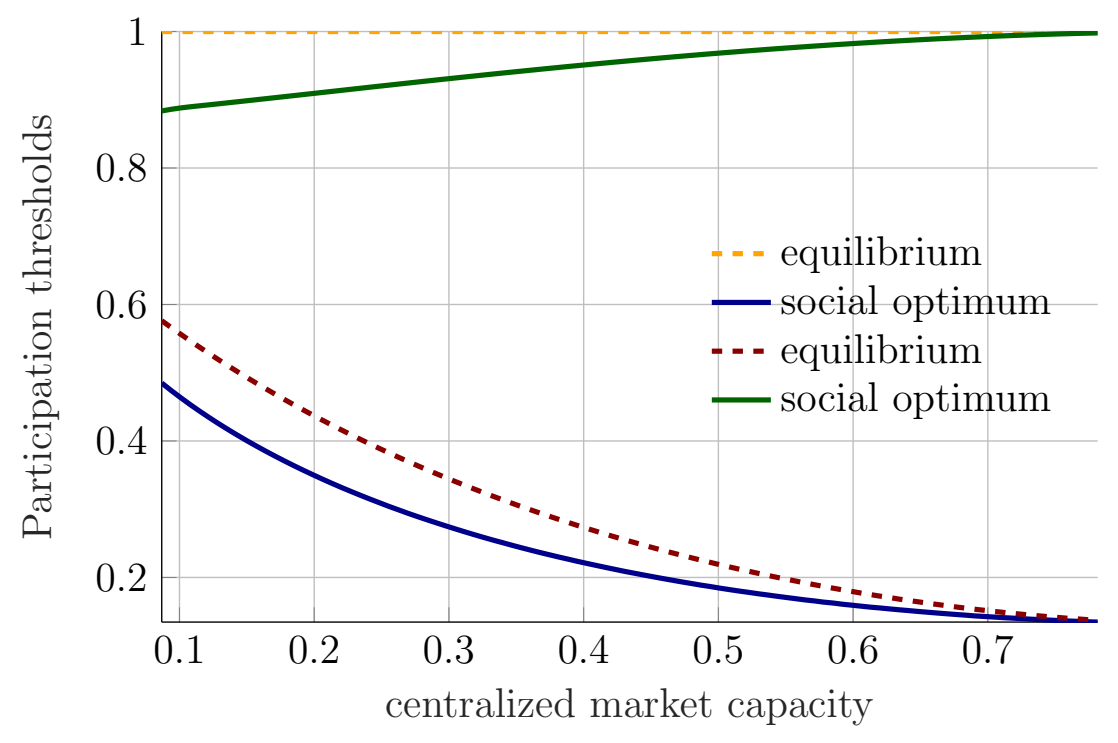

Figure 3: The participation thresholds as a function of the centralized market capacity, in the equilibrium vs. social optimum. The distribution of capacities is assumed to be uniform over $[0, \bar{k}]$, with $\bar{k}=1.496$.

the social optimum, in the sense that the post-trade exposure $\bar{g}_{\mathrm{o}}$ becomes closer to $1 / 2$, the full risk sharing benchmark.

\subsection{Exclusive vs. non-exclusive participation}

In this section we study whether the welfare results of Section 4.1, in which participation is taken to be exclusive, are robust to non-exclusive participation. Our two examples below confirm an observation made earlier in Section 3.3. Namely, the welfare result do not depend on exclusive participation per se, but on whether reallocating a marginal bank induces match creation and destruction in the OTC market. If the reallocation does not induce match creation and destruction, then it is always welfare reducing. If the reallocation induces match creation and destruction, then its effect is similar to the one discussed in the exclusive case.

Allowing for non-exclusive participation makes it harder to characterize equilibrium analytically. First, in contrast with Section 4.1, post-trade exposures in the OTC market are in general not equalized. Second, with more participation choices, the equilibrium becomes potentially more complex and so is harder to characterize. In order to simplify the analysis, we focus on a region of the parameter space such that participation is non-exclusive for a small fraction of 


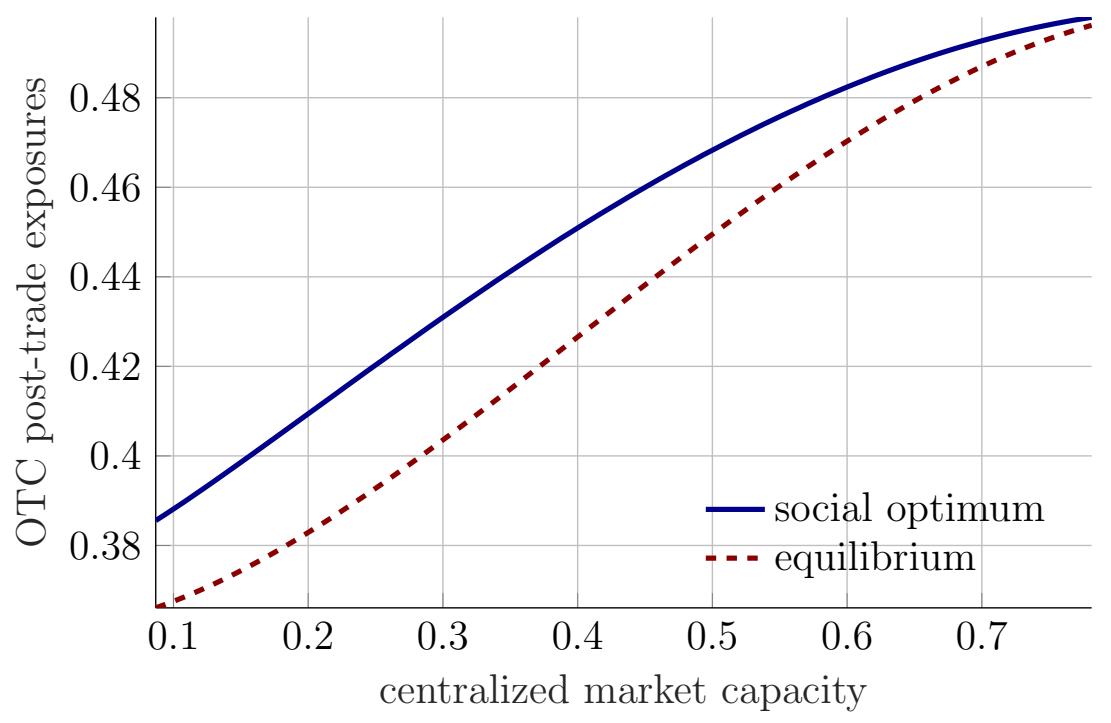

Figure 4: The OTC post-trade exposure as a function of the centralized market capacity, in the equilibrium vs. social optimum. The distribution of capacities is assumed to be uniform over $[0, \bar{k}]$, with $\bar{k}=1.496$.

banks. As will be clear below, this leads to a simple distribution of post-trade exposures in the OTC market and to intuitive equilibrium participation choices.

\subsubsection{A first example of non-exclusive participation}

As in the previous section, we assume heterogeneous capacities, distributed according to the density $f(k)$ over some interval $[\underline{k}, \bar{k}]$. We also keep the same trading capacity constraint. The difference with the previous section is the structure of participation costs. We assume that participating in the OTC market is free, $C(\mathrm{o})=0$, and participating in the centralized market, in addition or instead, entails a cost $C(\mathrm{oc})=C(\mathrm{c})=C$ which is relatively large. A natural interpretation is that of a pre-existing OTC market structure challenged by a novel electronic trading platform. Notice that this cost structure implies immediately that participation in the centralized market will always be non-exclusive: since $C(\mathrm{oc})=C(\mathrm{c})$, banks that choose to participate in the centralized also optimally participate in the OTC market.

Proposition 5. Suppose that capacities are distributed over the compact interval $[\underline{k}, \bar{k}]$, with $\underline{k}>0, \bar{k}+K<1$, and density $f(k)$ such that $\bar{k} f(\bar{k})>\frac{1}{2}$ and average capacity $\int k f(k) d k<1$. 
Then there is a participation cost $C$ and a participation threshold $k^{\star}$ such that, in equilibrium,

$$
\pi(0, k)=\pi(1, k)= \begin{cases}\text { o } & \text { if } k \in\left[\underline{k}, k^{\star}\right] \\ \text { oc } & \text { if } k \in\left(k^{\star}, \bar{k}\right] .\end{cases}
$$

Moreover, there are two atoms $\bar{g}_{\mathrm{o}}<\bar{g}_{\mathrm{oc}}$ such that

$$
g(0, k, \mathrm{o})=\bar{g}_{\mathrm{o}} \text { if } k \in\left[\underline{k}, k^{\star}\right] \text { and } g(0, k, \mathrm{oc})=\bar{g}_{\mathrm{oc}} \text { if } k \in\left(k^{\star}, \bar{k}\right] .
$$

Finally, the post-trade exposures of $\omega=1$ banks are symmetric to that of $\omega=0$ banks.

In the equilibrium of the Proposition, the atom property continues to hold, but conditional on endowment and participation decisions: that is, the atoms are different for banks who participate in the OTC market only, and for banks who participate in both markets. In particular, $\omega=0$ banks who only participate in the OTC market have post-trade exposure $\bar{g}_{\mathrm{o}}$, while $\omega=0$ banks who participate in both markets have higher post-trade exposure $\bar{g}_{\mathrm{oc}}$, reflecting the fact that participating in the centralized market expands risk-sharing opportunities. In turn, highcapacity banks have the strongest incentives to participate in the centralized market because they can purchase larger quantities and re-sell them to others in the OTC market.

In such an equilibrium, making the marginal bank, with capacity $k^{\star}$, participate in the centralized market in addition to the OTC market is welfare reducing. To see this, recall from the Proposition that when banks participate in the centralized market in addition to the OTC market, their post trade exposures become closer to the median, 1/2. But this means that their bargaining surplus per quantity traded in the OTC market becomes smaller, on average. Indeed, the bargaining surplus of a bank with post-trade exposure $g$ is proportional to the absolute distance between $g$ and the post-trade exposures of other banks. As is well known, such an average distance is minimized if $g$ is the median post-trade exposure.

\subsubsection{A second example of non-exclusive participation}

In this section, we show that the welfare analysis of non-exclusive and exclusive participation can, in some cases, be similar. This example illustrates that our results do not depend on exclusivity per se, but on whether the reallocation of banks to the centralized market induces match creation and destruction in the OTC market.

In the example, the participation patterns are the same as in the exclusive case, but with one difference: high-capacity banks participate both in the OTC and the centralized market 
instead of participating exclusively in the OTC market. In order to generate such participation patterns, we assume that the cost of participating in both market, $C(\mathrm{oc})$, is not too large, while participating exclusively in one market is free, that is $C(\mathrm{o})=C(\mathrm{c})=0$. For tractability, we consider the following "max" capacity constraint, ${ }^{22}$

$$
\Gamma\left(k, k^{\prime}\right)=\frac{1}{2} \max \left\{k, k^{\prime}\right\}
$$

In Appendix A.10, we study equilibria when capacities are uniformly distributed over the compact interval $[0,1]$, that the capacity of the centralized exchanged is nil, $K=0$, and that the non-exclusive participation cost is $C(\mathrm{oc})=\left|U_{g g}\right| / 16$. After deriving equilibrium post-trade exposures and marginal private values in closed form, we verify numerically that there are are participation thresholds $k^{\star}<k^{\star \star}$ such that, in equilibrium,

$$
\pi(0, k)=\pi(1, k)= \begin{cases}\text { o } & \text { if } k \in\left[\underline{k}, k^{\star}\right] \\ \text { c } & \text { if } k \in\left(k^{\star}, k^{\star \star}\right) \\ \text { oc } & \text { if } k \in\left[k^{\star \star}, \bar{k}\right] .\end{cases}
$$

In the OTC market:

$$
\begin{aligned}
g(0, k, \mathrm{o}) & =\bar{g}_{\mathrm{o}}<\frac{1}{2} \text { if } k \in\left[0, k^{\star}\right], \\
g(0, k, \mathrm{oc}) & =1 \text { if } k \in\left[k^{\star \star}, 1\right],
\end{aligned}
$$

and the post-trade exposures of $\omega=1$ banks are symmetric to that of $\omega=0$ banks. ${ }^{23}$ Moreover, the average bargaining surplus is in between the bargaining surpluses of the marginal banks,

$$
B\left(0, k^{\star}, \mathrm{o}\right)<\bar{B}<B\left(0, k^{\star \star}, \mathrm{oc}\right)
$$

The participation patterns are thus similar to the one in the example of Section 4.1, with the difference that high-capacity banks participate non-exclusively in both the OTC and the centralized market. We find that the post-trade exposures of low-capacity banks in the OTC market are equalized at $\bar{g}_{\mathrm{o}}<\frac{1}{2}$, while the post-trade exposures of the high-capacity banks who participate non-exclusively in the OTC and the centralized market are equalized at $\bar{g}_{\text {oc }}=\frac{1}{2}$.

\footnotetext{
${ }^{22}$ In Section D, we show that this specification preserves the two layers of "core-periphery" structure and the welfare implications of our leading example.

${ }^{23}$ We also verified that the equilibrium existence is robust to small variations of $C\left(\right.$ oc) around $\left|U_{g g}\right| / 16$.
} 
As it turns out, the welfare analysis of this equilibrium is also similar to the exclusive example of Section 4.1. This is because moving a marginal bank to the centralized market, from $\pi=\mathrm{o}$ to $\pi=\mathrm{c}$ or from $\pi=$ oc to $\pi=\mathrm{c}$, induces match creation and destruction in the OTC market. As before, the welfare effect is governed by the comparison between the bargaining surplus of the marginal bank, and the average bargaining surplus in the OTC market. Hence, we find that moving a low-capacity marginal bank $\left(k^{\star}\right)$ to the centralized market is welfare improving, while moving a high-capacity marginal bank $\left(k^{\star \star}\right)$ to the centralized market is welfare reducing.

\subsection{Heterogeneous capacities vs. heterogeneous endowments}

In this section, we show that the welfare analysis depends on the type of heterogeneity: if banks are heterogeneous in endowment, then moving customer banks to the centralized market is welfare reducing instead of welfare improving. We establish this result under the following assumptions. First, banks now are heterogeneous in their endowment: the distribution of $\omega$ across banks is uniform over the interval $[0,1]$. Second, banks are homogeneous in their trading capacities: the trading capacity constraint is $\Gamma\left(x, x^{\prime}\right)=\Phi(x)=k$ for all $x$ and $x^{\prime}$ and some $k<\frac{1}{2}$. Third, participation costs $C(\pi)$ induce exclusive participation: optimal participation choices are either $\pi=\mathrm{o}$ or $\pi=\mathrm{c}$. We also require in this case that $C(\mathrm{o})<C(\mathrm{c})$, otherwise the centralized market would always dominate the OTC market. ${ }^{24}$

We guess and verify that, under parameter restrictions to be determined, there exists a symmetric equilibrium in which extreme- $\omega$ banks, who have the strongest risk-sharing needs, participate exclusively in the centralized market, which is the most efficient trading venue. Middle- $\omega$ banks, on the other hand, participate exclusively in the OTC market. ${ }^{25}$ Formally, and keeping in mind that participation is symmetric, there is some $\omega^{\star} \in\left[0, \frac{1}{2}\right]$ such that banks

\footnotetext{
${ }^{24}$ Our ranking of participation costs is that a centralized market typically imposes more stringent regulatory requirements than OTC markets, involves reengineering of participants' infrastructure to prepare for electronic trading, and requires costly membership to a central clearing party (CCP). Securities and Exchange Commission (2011) discusses technological, regulatory, and disclosure costs of trading in centralized Swap Execution Facilities (SEF). In a survey about the incremental costs resulting from the mandate to migrate trade to SEFs, ISDA Research Staff (2011) reports that Buy-Side users "expect to spend an average of $\$ 2.1$ million in technology, $\$ 1.3$ million amending client/counterparty documentation and $\$ 200$ thousand (annually) in additional regulatory reporting." Finally, Duffie, Li, and Lubke (2010) state that "beyond demonstrating its financial strength and providing margin, each CCP member must also contribute capital to a pooled CCP guarantee fund. The guarantee fund is an additional layer of defense, after initial margin, to cover losses stemming from the failure of a member to perform on a cleared derivative."

${ }^{25}$ These participation patterns are similar to the one obtained by Gehrig (1993) and Miao (2006), who consider models in which investors differ in their private valuation, which is conceptually analogous to our assumption that banks differ in their initial endowment. In these papers, however, all investors participate as customers in the OTC market.
} 
with $\omega \in\left[0, \omega^{\star}\right) \cup\left(1-\omega^{\star}, 1\right]$ participate in the centralized market, and banks with $\omega \in\left[\omega^{\star}, 1-\right.$ $\left.\omega^{\star}\right]$ participate in the OTC market. Notice that, while these participation patterns are nonmonotonic in endowment, they are in fact monotonic in risk-sharing need: two banks with symmetric endowment $\omega$ and $1-\omega$ have in fact identical risk-sharing needs.

Lastly, we guess and verify later that $\omega^{\star}$ satisfies $\omega^{\star}+k<\frac{1}{2}$. As will be clear below, this ensures that the marginal bank shares risk imperfectly in the OTC market, and so faces meaningful trade-off between the OTC and the centralized market.

Equilibrium conditional on participation. We first characterize trading patterns in the OTC market.

Lemma 5. Given our conjectured participation patterns, post-trade exposures in the OTC and the centralized market are:

$$
\begin{aligned}
& g(\omega, k, \mathrm{c})=\min \left\{\omega+k, \frac{1}{2}\right\} \text { for } \omega \leq \frac{1}{2} \\
& g(\omega, k, \mathrm{c})=\max \left\{\omega-k, \frac{1}{2}\right\} \text { for } \omega \geq \frac{1}{2} \\
& g(\omega, k, \mathrm{o})=\omega+k[1-2 N(\omega \mid \mathrm{o})],
\end{aligned}
$$

where $N(\omega \mid \mathrm{o})$ is the cumulative distribution of endowments of OTC market participants.

Figure 5 illustrates the post-trade exposures conditional on $\pi=\mathrm{c}$ and $\pi=\mathrm{o}$. To understand the formula for post-trade exposures in the centralized market, recall that the centralized market price is $U_{g}\left(\frac{1}{2}\right)$. Therefore, an $\omega \in\left[0, \frac{1}{2}\right]$ bank buys as much as allowed by its trading capacity, subject to not exceeding a post-trade exposure of $\frac{1}{2}$. We obtain the formula for the post-trade exposures in the OTC market by guessing that $g(\omega, k, \mathrm{o})$ is strictly increasing in $\omega$. Then, the optimality condition (8) implies that an $\omega$ trader always sells $k$ units to $\omega^{\prime}<\omega$ traders, and purchases $k$ units from $\omega^{\prime}>\omega$ traders:

$$
g(\omega, k, \mathrm{o})=\omega-k N(\omega \mid \mathrm{o})+k[1-N(\omega \mid \mathrm{o})]
$$

Given our assumed participation decisions and given uniform distribution,

$$
N(\omega \mid \text { o })= \begin{cases}0 & \text { if } \omega \in\left[0, \omega^{\star}\right) \\ \frac{\omega-\omega^{\star}}{1-2 \omega^{\star}} & \text { if } \omega \in\left[\omega^{\star}, \frac{1}{2}\right]\end{cases}
$$




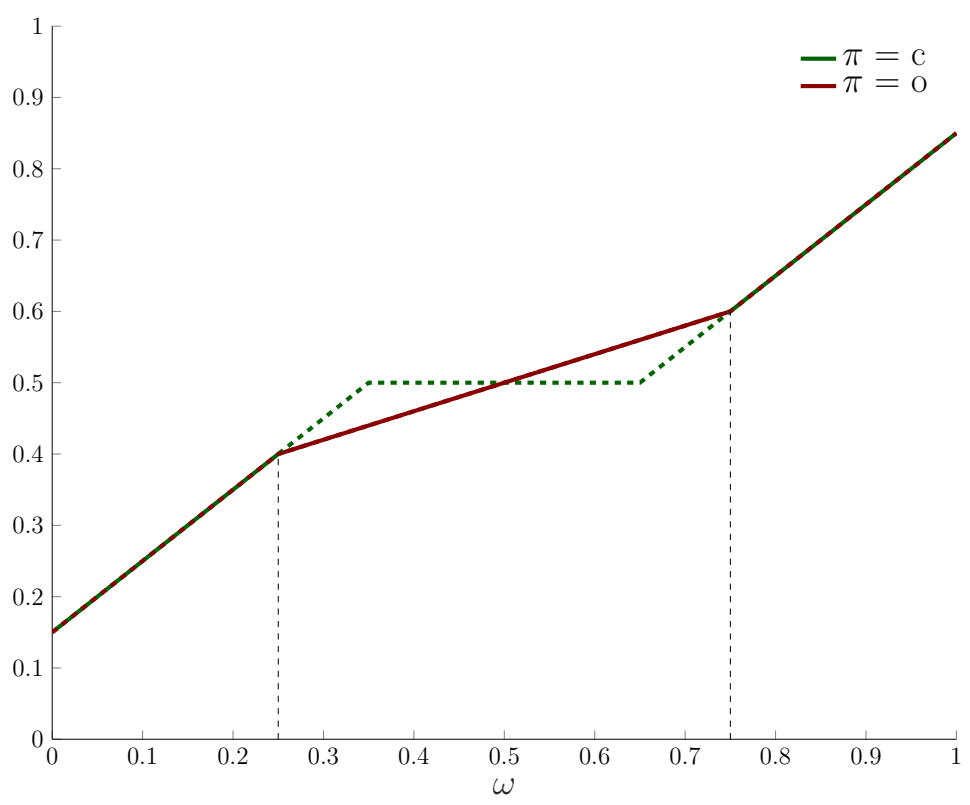

Figure 5: Post-trade exposures as a function of endowment in the example with heterogeneous endowment and exclusive participation. Plain lines show the post-trade exposure on the participation path, that is, conditional on a bank's actual participation decision. Dotted lines show the post-trade exposure off the participation path, conditional on making the alternative exclusive market participation decision.

and, by symmetry, $N(\omega \mid 0)=1-N(1-\omega \mid 0)$ for $\omega \geq \frac{1}{2}$. Plugging the expression for the conditional distribution in (16), and keeping in mind that $\omega^{\star}+k<\frac{1}{2}$, one easily sees that $g(\omega, k, o)$ is strictly increasing, so our guess is verified. ${ }^{26}$

As in AEW, banks with extreme $\omega$ trade like "customers," in the sense that most of their trades go in the same direction. Specifically, low- $\omega$ banks mostly purchase assets, and high- $\omega$ banks mostly sell assets. Middle- $\omega$ banks, on the other hand, trade like "intermediaries." They trade in all directions, buying from high- $\omega$ banks and selling to low- $\omega$ banks.

Optimal participation and equilibrium existence. Next, we determine the optimal participation decision by studying the relative incentives to participate in the centralized vs. the OTC market.

Lemma 6. Given our conjectured participation patterns, the difference between the MPV of participating in the centralized market and that of participating in the OTC market $\operatorname{MPV}(\omega, k, \mathrm{c})-$ $\operatorname{MPV}(\omega, k, \mathrm{o})$ is strictly $U$-shaped and symmetric around $\omega=\frac{1}{2}$.

\footnotetext{
${ }^{26}$ As before, the formula (16) applies on and off the participation path, for all banks: the one who actually decide to participate in the OTC market (in the support of $N(\omega \mid$ o) ) and the one who do not (outside the support). Figure 5 shows $g_{\mathrm{o}}(\omega)$, with plain lines for the banks in the support and with dotted lines for the banks outside the support.
} 
Lemma 6 shows that extreme- $\omega$ banks' incentives to participate in the centralized market dominates their incentives to participate in the OTC market, which confirms our guess about participation patterns.

Let us focus on the trade-off faced by the marginal bank. In the OTC market, this bank only meets counterparties with strictly larger post-trade exposures, so it purchases $k$ in all of its bilateral meeting. Hence, its post-trade exposure is

$$
g\left(\omega^{\star}, k, \mathrm{o}\right)=\omega^{\star}+k
$$

Given that the capacity constraint applies in all markets, the bank reaches the same post-trade exposure in the centralized market, $g\left(\omega^{\star}, k, \mathrm{c}\right)=\omega^{\star}+k$. Yet, the MPVs are not the same because terms of trade are different. In the centralized market, the price is $U_{g}\left(\frac{1}{2}\right) .{ }^{27}$ In the OTC market, the average price paid by the marginal bank is:

$$
\frac{1}{2}\left[U_{g}\left(g\left(\omega^{\star}, k, \mathrm{c}\right)\right)+U_{g}\left(\frac{1}{2}\right)\right],
$$

since the average marginal value across all OTC counterparties is $U_{g}\left(\frac{1}{2}\right)$. So one sees that, because of bargaining, the marginal bank buys at higher prices in the OTC market than in the centralized market. All in all, and keeping in mind that $C(\mathrm{o})<C(\mathrm{c})$, the marginal bank trades off better terms of trade in the centralized market, with lower participation costs in the OTC market.

To obtain the equilibrium equation for $\omega^{\star}$, we calculate the difference between the MPV in the two markets. As argued above, it only reflects differences in terms of trade: it is equal to the quantity times the price difference between the centralized and the OTC market:

$$
\operatorname{MPV}\left(\omega^{\star}, k, \mathrm{c}\right)-\operatorname{MPV}\left(\omega^{\star}, k, \mathrm{o}\right)=k \frac{\left|U_{g g}\right|}{2}\left(\frac{1}{2}-\omega^{\star}-k\right)=C(\mathrm{c})-C(\mathrm{o}) .
$$

It is then straightforward to adapt the argument of Lemma 6 and show that the conjectured participation patterns are optimal.

\footnotetext{
${ }^{27}$ Notice that there are multiple market-clearing prices in the centralized market, since the trading capacity constraint is binding for all banks. However, $U_{g}\left(\frac{1}{2}\right)$ is the only price consistent with symmetric participation incentives, and so with a symmetric participation equilibrium.
} 
Welfare analysis. An application of the general envelope analysis of Proposition 2 to this special case implies that reallocating banks near the $\omega^{\star}$ margin from the OTC to the centralized market is welfare improving if and only if $B\left(\omega^{\star}, k, \mathrm{o}\right)-\bar{B}<0$, which does not hold in equilibrium.

The result arises because the marginal bank has the strongest unfulfilled risk-sharing needs. In equilibrium, the distance between its post-trade exposure and the post-trade exposures of other banks participating in the OTC market is largest. Correspondingly, it creates a larger bargaining surplus per quantity traded than any other bank participating in the OTC market. Hence, by reallocating a marginal bank from the OTC market to the centralized market, the social planner destroys matches in which the surplus per quantity traded is large, and creates matches in which the surplus per quantity traded is small. Since we are assuming here that banks have the same capacity, the trade size is the same in all matches. Hence, the reallocation of the marginal bank reduces welfare.

We conclude that, with heterogeneity in endowments, the centralized market is inefficiently large. Encouraging further centralized market participation is welfare reducing.

\subsection{Empirical implications of different heterogeneities}

Our analytical examples suggest that, when participation is exclusive, increasing customer participation in centralized market may be welfare improving when banks differ mostly in their ability to take large positions (trading capacity), but is welfare reducing when banks differ mostly in their risk-sharing needs (endowment). Therefore, it is crucial to empirically distinguish an economy in which banks differ mostly in terms of their trading capacities, from an economy in which banks differ mostly in terms of their risk-sharing needs. To do so, we study banks' net and gross OTC trading volume, defined as:

$$
\begin{aligned}
& N V(x) \equiv \int \gamma\left(x, x^{\prime}\right) d N\left(x^{\prime} \mid \mathrm{o}\right)=g(x)-\omega(x), \\
& G V(x) \equiv \int\left|\gamma\left(x, x^{\prime}\right)\right| N\left(x^{\prime} \mid \mathrm{o}\right) .
\end{aligned}
$$

Using results from Sections 4.1 and 4.3, we obtain the following proposition.

Proposition 6. In our analytical example with heterogeneous trading capacity and homogeneous risk-sharing need, and given the bilateral trades (14):

$$
\frac{\partial N V}{\partial k}(\omega, k, \mathrm{o})=0 \text { and } \frac{\partial G V}{\partial k}(\omega, k, \mathrm{o})>0
$$


In our analytical example with homogeneous trading capacity and heterogeneous risk-sharing need,

$$
\frac{\partial N V}{\partial \omega}(\omega, k, \mathrm{o})<0 \text { for } \omega<\frac{1}{2}, \frac{\partial N V}{\partial \omega}(\omega, k, \mathrm{o})>0 \text { for } \omega>\frac{1}{2} \text {, and } \frac{\partial G V}{\partial \omega}(\omega, k, \mathrm{o})=0 \text {. }
$$

The Proposition implies that, in our example with heterogeneous trading capacity, the net volume is independent of capacity, $k$. Indeed, banks with identical endowment have identical post-trade exposures, and so have identical net volume. The gross volume, on the other hand, is increasing in $k$. In contrast, in our example with heterogeneous endowment, the net volume is largest for banks with extreme endowments, and smallest for banks with intermediate endowments. Indeed intermediate-endowment banks provide intermediation services precisely because they do not need to use their capacity to change their net exposures. The gross volume, on the other hand, is the same for all banks. This is because all banks have the same trading capacity, $k$, and because there are strict gains from trade in all bilateral matches. Therefore, the same quantity is traded in all bilateral matches for all banks, leading to constant gross volume.

Stylized facts. Empirical evidence suggests that dealers concentrate a very large fraction of gross volume (Bech and Atalay, 2010; Di Maggio, Kermani, and Song, 2017; Hollifield, Neklyudov, and Spatt, 2017; Li and Schürhoff, 2019). This observation holds after controlling for natural measure of bank size (see for example Atkeson, Eisfeldt, and Weill, 2013, for the CDS market), which is relevant for our model in which all banks have the same number of traders and hence the same size. This observation is better in line with the heterogeneous capacity model, in which the gross volume of dealers is larger than that of customers since $\frac{\partial G V}{\partial k}>0$ according to Proposition 6. In the heterogeneous endowment model, by contrast, all agents have the same gross volume.

Siriwardane (2018) reports empirical evidence about net volume in the context of CDS markets: he finds that dealers also concentrate a very large fraction of net buying and net selling volumes. This is in contradiction with the heterogeneous endowment model in which dealers tend to have lower net volume than customers since $\frac{\partial N V}{\partial \omega}<0$ for $\omega \leq 1 / 2$ according to Proposition 6. Again, it can be argued that the heterogeneous capacity model is better in line with that piece of evidence, because dealers' net volume is as high as customers' in the heterogeneous capacity model. 


\section{Conclusion}

We developed a model of costly participation of heterogeneous banks in an OTC and/or a centralized market. The equilibrium generates rich participation and trading patterns and can be used to evaluate the social value of policies that reallocate banks across markets. We highlight the two main determinants of welfare change stemming from a reallocation of marginal banks: (i) whether the reallocation leads to match creation and destruction in the OTC market and (ii) the type of heterogeneity. For cases where there is no match creation/destruction from reallocating a marginal bank, we find that such interventions are always welfare reducing. However, we also find that if banks differ in their ability to take large positions and if there is match creation and destruction, reallocating marginal OTC market customers to the centralized market is welfare improving, but reallocating marginal dealers is welfare reducing. 


\section{References}

Gara Afonso and Ricardo Lagos. Trade dynamics in the market for federal funds. Econometrica, $83: 263-313,2015$.

Charalambos D. Aliprantis and Kim C. Border. Infinite Dimensional Analysis: A Hitchhiker's Guide. Springer-Verlag Berlin Heidelberg, 3rd edition edition, 2006.

David Andolfatto. Business cycles and labor-market search. American Economic Review, 86 (1):112-132, 1996.

Andrew G. Atkeson, Andrea L. Eisfeldt, and Pierre-Olivier Weill. The market for otc credit derivatives. Working paper, UCLA, 2013.

Andrew G. Atkeson, Andrea L. Eisfeldt, and Pierre-Olivier Weill. Entry and exit in over-thecounter markets. Econometrica, 83:2231-2292, 2015.

Ulf Axelson. Security design with investor private information. Journal of Finance, 62(6): $2587-2632,2007$.

Ana Babus. Endogenous intermediation in over-the-counter markets. Working paper, Federal Reserve Bank of Chicago, 2009.

Ana Babus and Kinda Cheryl Hachem. Markets for financial innovation. Working paper, 2019.

Ana Babus and Péter Kondor. Trading and information diffusion in over-the-counter markets. Econometrica, 86(5):1727-1769, 2018.

Ana Babus and Cecilia Parlatore. Strategic fragmented markets. Working paper, 2017.

Francis Bach. Submodular functions: from discrete to continuous domains. Mathematical Programming, 175:419-459, 2019.

Morten L. Bech and Enghin Atalay. The topology of federal funds market. Physica A, 389(22): 5223-5246, 2010.

Zachary Bethune, Bruno Sultanum, and Nicholas Trachter. An information-based theory of financial intermediation. Working paper, 2018.

Bruno Biais and Richard Green. The microstructure of the bond market in the 20th century. Working paper, TSE, HEC, and CMU, 2006. 
Bruno Biais and Thomas Mariotti. Strategic liquidity supply and security design. Review of Economic Studies, 72:615-649, 2005.

Sushil Bikhchandani and Joseph M. Ostroy. The package assignment model. Journal of Economic Theory, 107:377-406, 2002.

Jeremy Bulow and Paul Klemperer. Why do sellers (usually) prefer auctions? American Economic Review, 99(4):1544-1575, 2009.

Giovanni Cespa and Xavier Vives. Exchange competition, entry, and welfare. Working paper, 2018.

Briana Chang and Shengxin Zhang. Endogenous market making and network formation. Working paper, 2016.

Allan Collard-Wexler, Gautam Gowrisankaran, and Robin S. Lee. "Nash-in-Nash" bargaining: A microfoundation for applied work. Journal of Political Economy, 127(1):163-195, 2019.

Jean-Edouard Colliard, Thierry Foucault, and Peter Hoffmann. Inventory management, dealers' connections, and prices in over-the-counter markets. 2021.

Gregory S. Crawford and Ali Yurukoglu. The welfare effects of bundling in multichannel television markets. American Economic Review, 102(2):643-685, 2012.

Vincent P. Crawford and Elsie M. Knoer. Job matching with heterogeneous firms and workers. Econometrica, 49:437-450, 1981.

Calebe de Rourea, Emanuel Moench, Loriana Pelizzon, and Michael Schneider. OTC discount. Working paper, 2020.

Marco Di Maggio, Amir Kermani, and Zhaogang Song. The value of trading relations in turbulent times. Journal of Financial Economics, 124(2):266-284, 2017.

Darrell Duffie, Ada Li, and Theo Lubke. Policy perspectives on otc derivatives market infrastructure. Federal Reserve Bank of New York Staff Report no. 424, March 2010.

Ivan Eckland and Roger Témam. Convex Analysis and Variational Problems. Society for Industrial Mathematics, 1987. 
Maryam Farboodi, Gregor Jarosch, and Robert Shimer. The emergence of market structure. Working paper, 2015.

Maryam Farboodi, Gregor Jarosch, and Guido Menzio. Intermediation as rent extraction. Working paper, 2016.

Financial Stability Board. Otc derivatives market reform, twelfth progress report on implementation. Technical report, 2017.

Thomas Gehrig. Intermediation in search markets. Journal of Economics and Management Strategy, 2:97-120, 1993.

Athanasios Geromichalos and Lucas Herrenbrueck. Monetary policy, asset prices, and liquidity in over-the-counter markets. Journal of Money, Credit, and Banking, 48(1):35-79, 2016.

Vincent Glode and Christian C. Opp. Over-the-counter vs. limit-order markets: The role of traders' expertise. Review of Financial Studies, 33:866-915, 2020.

Terrence Hendershott, Dan Li, Dmitry Livdan, and Norman Schürhoff. Relationship trading in over-the-counter markets. Journal of Finance, 75(2):683-734, 2020.

Craig H. Holden, Dong Lu, Volodymyr Lugovskyy, and Daniela Puzzello. What is the impact of introducing a parallel OTC market? theory and evidence from the chinese interbank FX market. Journal of Financial Economics, 140:270-291, 2021.

Burton Hollifield, Artem Neklyudov, and Chester Spatt. Bid-ask spreads, trading networks, and the pricing of securitizations. The Review of Financial Studies, 30(9):3048-3085, 2017.

Henrick Horn and Asher Wolinsky. Bilateral monopolies and incentives for merger. RAND Journal of Economics, 19(3):408-419, 1988.

Arthur J. Hosios. On the efficiency of matching and related models of search and unemployment. The Review of Economic Studies, 57:279-298, 1990.

Julien Hugonnier, Benjamin Lester, and Pierre-Olivier Weill. Heterogeneity in decentralized asset market. Working paper, 2014.

ISDA Research Staff. Costs and benefits of mandatory electronic execution requirements for interest rate products. Discussion Papers Series 2, International Swaps and Derivatives Association, Inc., 2011. 
Kei Kawakami. Welfare consequences of information aggregation and optimal market size. American Economic Journal: Microeconomics, 9(4):303-323, 2017.

Tjalling C. Koopmans and Martin Beckmann. Assignment problems and the location of economic activities. Econometrica, 25:53-76, 1957.

Tomy Lee and Chaojun Wang. Why trade over the counter? when investors want price discrimination. Working paper, 2018.

Dan Levin and James L. Smith. Equilibrium in auctions with entry. American Economic Review, 84(3):585-599, 1994.

Dan Li and Norman Schürhoff. Dealer networks. Journal of Finance, 74(1):91-144, 2019.

Wei Li and Zhaogang Song. Dealers as information intermediaries in over-the-counter markets. Working paper, 2019.

Ying Liu, Sebastian Vogel, and Yuan Zhang. Electronic trading in otc markets vs. centralized exchange. Working paper, 2018.

Robert E. Jr. Lucas. Liquidity and interest rates. Journal of Economic Theory, 50:237-264, 1990.

David G. Luenberger. Optimization by Vector Space Methods. Wiley, John and Sons, New York, 1969.

Semyon Malamud and Marzena Rostek. Decentralized exchange. American Economic Review, 107(11):3320-3362, 2017.

N. Gregory Mankiw and Michael D. Whinston. Free entry and social inefficiency. RAND Journal of Economics, 17(1):48-58, 1986.

Preston R. McAfee and John McMillan. Auctions with entry. Economics Letters, 23:343-347, 1987.

Flavio M. Menezes and Paulo K. Monteiro. Auctions with endogenous participation. Review of Economic Design, 5:71-89, 2000.

Jianjun Miao. A search model of centralized and decentralized trade. Review of Economic Dynamics, 9(1):68-92, 2006. 
Paul Milgrom and Ilya Segal. Envelope theorem for arbitrary choice sets. Econometrica, 2: 583-601, 2002.

John Nachbar. Fixed point theorems. Technical report, Washington University in St. Louis, 2017.

Artem Neklyudov. Bid-ask spreads and the over-the-counter interdealer markets: Core and peripheral dealers. Working paper, CMU, 2012.

Marina Núñez and Carles Rafels. A survey on assignment markets. Journal of Dynamics and Games, 2:227-256, 2015.

Remy Praz. Essays in Asset Pricing with Search Frictions. PhD thesis, École Polytechnique Fédérale de Lausanne, 2014.

Lynn Riggs, Esen Onur, David Reiffen, and Haoxiang Zhu. Swap trading after dodd-frank: Evidence from index cds. Working paper CFTC and MIT, 2018.

Marzena Rostek and Ji Hee Yoon. Decentralized markets and derivatives. Working paper, 2018.

Halsey L. Royden and Patrick M. Fitzpatrick. Real Analysis. Pearson, 4th edition, 2010.

John Rust and George Hall. Middlemen versus market makers: A theory of competitive exchange. Journal of Political Economy, 111(2):pp. 353-403, 2003.

Securities and Exchange Commission. Registration and regulation of security-based swap execution facilities. Exchange Act Release 34-63825, Federal Register, 2011.

Lloyd S. Shapley and Martin Shubik. The assignment game i: The core. International Journal of Game Theory, 1(111-130), 1972.

Shouyang Shi. A divisible search model of fiat money. Econometrica, 65:75-102, 1997.

Robert Shimer. Labor Markets and Business Cycles (CREI Lectures in Macroeconomics). Princeton University Press, 2010.

Emil Siriwardane. Limited investment capital and credit spreads. Journal of Finance, Forthcoming, 2018.

Lars A. Stole and Jeffrey Zwiebel. Intra-firm bargaining under nonbinding contracts. The Review of Economic Studies, 63(3):375-410, 1996. 
Semih Üslü. Pricing and liquidity in decentralized asset markets. Econometrica, 87:2079-2140, 2019.

Sebastian Vogel. When to introduce electronic trading platforms in over-the-counter markets? Working paper, 2019.

Chaojun Wang. Core-periphery trading networks. Working paper, 2016.

Abdullah Yavaş. Marketmakers versus matchmakers. Journal of Financial Intermediation, 2: 33-58, 1992.

Ji Hee Yoon. Endogenous market structure: Over-the-counter versus exchange trading. Working paper, 2018. 